NBER WORKING PAPER SERIES

\title{
HEALTH, HUMAN CAPITAL AND DOMESTIC VIOLENCE
}

\author{
Nicholas W. Papageorge \\ Gwyn C. Pauley \\ Mardge Cohen \\ Tracey E. Wilson \\ Barton H. Hamilton \\ Robert A. Pollak \\ Working Paper 22887 \\ http://www.nber.org/papers/w22887
}

\section{NATIONAL BUREAU OF ECONOMIC RESEARCH \\ 1050 Massachusetts Avenue \\ Cambridge, MA 02138}

December 2016, Revised July 2019

\begin{abstract}
We gratefully acknowledge helpful comments from: Anna Aizer, Elizabeth Ananat, David Bishai, Christopher Carpenter, John Cawley, Ying Chen, Stefanie Deluca, Kathryn Edin, Emmanuel Garcia, Seth Gershenson, Ali Khan, Gizem Kosar, Giulia La Mattina, Robert Moffitt, Daniel Rees, Victor Ronda, Wayne Roy-Gayle, Todd Stinebrickner, Erdal Tekin and Matthew Wiswall along with participants at the IZA's 6th Annual Meeting on the Economics of Risky Behaviors, Royal Holloway, the 2014 North American Summer Meetings of the Econometric Society, the 2015 ASSA meetings, and the 2015 Southern Economics Association meetings. The usual caveats apply. The views expressed herein are those of the authors and do not necessarily reflect the views of the National Bureau of Economic Research.
\end{abstract}

At least one co-author has disclosed a financial relationship of potential relevance for this research. Further information is available online at http://www.nber.org/papers/w22887.ack

NBER working papers are circulated for discussion and comment purposes. They have not been peer-reviewed or been subject to the review by the NBER Board of Directors that accompanies official NBER publications.

(C) 2016 by Nicholas W. Papageorge, Gwyn C. Pauley, Mardge Cohen, Tracey E. Wilson, Barton H. Hamilton, and Robert A. Pollak. All rights reserved. Short sections of text, not to exceed two paragraphs, may be quoted without explicit permission provided that full credit, including (C) notice, is given to the source. 
Health, Human Capital and Domestic Violence

Nicholas W. Papageorge, Gwyn C. Pauley, Mardge Cohen, Tracey E. Wilson, Barton H. Hamilton, and Robert A. Pollak

NBER Working Paper No. 22887

December 2016, Revised July 2019

JEL No. I12,J24

\begin{abstract}
We study the impact of a medical breakthrough (HAART) on domestic violence and illicit drug use among low-income women infected with HIV. To identify causal effects, we assume that variation in women's immune system health when HAART was introduced affected how strongly their experience of domestic violence or drug use responded to the breakthrough. Immune system health is objectively measured using white blood cell (CD4) counts. Because the women in our sample were informed of their CD4 count, it is reasonable to assume they react to it. Using this identification strategy, we find that HAART introduction reduced domestic violence and illicit drug use. To explain our estimates, we treat health as a form of human capital and argue that women with more human capital face stronger incentives to make costly investments with future payoffs, such as avoiding abusive partners or reducing illicit drug use.
\end{abstract}

Nicholas W. Papageorge

Department of Economics

Johns Hopkins University

3400 N. Charles Street

Baltimore, MD 21218

and IZA

and also NBER

papageorge@jhu.edu

Gwyn C. Pauley

Schaeffer Center for Health Policy \& Economics

University of Southern California

635 Downey Way

VPD 2nd Floor

Los Angeles, CA 90089

gwyn.pauley@gmail.com

Mardge Cohen

Department of Medicine

Rush University and Stroger Hospital

1653 W. Congress Parkway

Chicago, IL 60612

mardge.cohen@gmail.com
Tracey E. Wilson

SUNY Downstate Medical Center

School of Public Health

450 Clarkson Avenue, Box 43

Brooklyn, NY 11203

Tracey.Wilson@downstate.edu

Barton H. Hamilton

Olin Business School

Washington University in St. Louis

Campus Box 1133

One Brookings Dr.

St. Louis, MO 63130

hamiltonb@wustl.edu

Robert A. Pollak

Washington University in St. Louis

Arts and Sciences

and the Olin Business School

Campus Box 1133

1 Brookings Drive

St. Louis, MO 63130-4899

and IZA

and also NBER

pollak@wustl.edu 


\section{Introduction}

Domestic violence is tragic, rampant, and costly. In the U.S., there are about 4.5 million instances of domestic violence each year, and about $22 \%$ of women will be physically assaulted by an intimate partner at least once in their lives (Tjaden and Thoennes, 2000). The annual cost of domestic violence - including direct medical expenditures and losses to productivity — is estimated at $\$ 5.8$ billion 11

Counting productivity losses as well as direct healthcare expenditures highlights two important relationships. The first is the well-established relationship between domestic violence and poor labor market outcomes. This relationship reflects how factors such as low education or drug abuse can increase the likelihood of violence and simultaneously discourage successful employment. Previous literature has shown that it also reflects causality in both directions. Abuse can deter human capital accumulation or undermine a woman's success at work, and women with few resources, poor labor market prospects or low earnings have fewer options outside violent partnerships (Browne et al., 1999; Swanberg and Macke, 2006, Aizer, 2010).

Less understood is the relationship between health and domestic violence. Poor health and chronic illness have been shown to be associated with abuse, once again reflecting how underlying factors (e.g., lack of education and drug abuse) contribute to both (Black et al., 2011). Mechanically, this relationship is also causal, at least in one direction: violence, by its nature, potentially damages health. However, scant attention has been paid to the causal effect of health on a woman's likelihood of suffering abuse.

This paper studies the impact of the introduction of a breakthrough medical innovation, Highly Active Anti-Retroviral Therapy (HAART), on domestic violence among a sample of

\footnotetext{
${ }^{1}$ Further costs accrue through spillover effects in classrooms (Carrell and Hoekstra, 2010), intergenerational persistence (Pollak, 2004), emotional duress and compromised quality of life. The above estimate also does not include costs to the justice system or social services and so $\$ 5.8$ billion is probably a gross under-estimation of the true economic costs of domestic violence.
} 
women who are infected with HIV (HIV-positive, henceforth $H I V+)^{2}$ A threshold question is why we might expect HAART to reduce violence. As we explain below, our analysis focuses on women who were HIV+, but not yet symptomatic. For these women, HAART lengthened expected lifespans, which incentivized them to make costly upfront investments with future payoffs. In our analysis, we treat the avoidance of domestic violence, including exiting an abusive relationship, as such an investment. While the benefits are obvious, the immediate costs of avoiding domestic violence may include temporary homelessness or escalated threats of physical harm when a woman attempts to leave an abusive partner ${ }^{3}$ More broadly, we view health as a form of human capital that not only increases longevity, but also improves the quality of life and increases labor market productivity Grossman, 1972; Becker, 2007). Viewed in this way, HAART enhanced women's expected future wellbeing and economic resources, such as income, further improving options outside of violent partnerships. Following similar logic, we assess the effect of HAART on another investment with upfront costs and future payoffs: reducing use of illicit drugs. Upfront costs include withdrawal symptoms and depression, while benefits include better future health and fewer barriers to employment. Consistent with the view that a medical innovation can incentivize these types of investments, we find that HAART led to decreases in both domestic violence and illicit drug use among HIV+ women.

Our study uses data from a longitudinal study, the Women's Intra-Agency HIV Study (henceforth, WIHS), which provides rich information on health, sociodemographic characteristics, domestic violence and illicit drug use. Women in the sample are predominantly black and report lower income and educational attainment than average U.S. women. This is an appropriate sample for our study since U.S. women with these characteristics are dis-

\footnotetext{
${ }^{2} \mathrm{HIV}$ stands for Human Immunodeficiency Virus. Without treatment, a newly infected HIV+ individual lives an average of 11 years. There is no vaccine or cure for HIV, but HAART is the current standard treatment. In general, 1996 is marked as the year when two crucial clinical guidelines that comprise HAART came to be commonly acknowledged. First, protease inhibitors (made widely available towards the end of 1995) would be an effective HIV treatment. Second, several anti-retroviral drugs taken simultaneously would vastly increases survival rates of HIV+ individuals. HAART transformed HIV infection from a lethal to a chronic condition (Yeni, 2006).

3 Zorza (1991) provides evidence that fleeing domestic abuse is a key cause of homelessness among women.
} 
proportionately affected by HIV (Pellowski et al., 2013) $4^{4}$ Moreover, three key features of HIV make it an appropriate setting for our study. First, the severity of HIV infection coupled with the effectiveness of HAART resulted in effect sizes large enough to detect the nuanced causal effects of a medical innovation on domestic violence and drug use. Untreated HIV leads to immune system deterioration (known as AIDS) after which fairly routine infections cause grave symptoms, illness and death 5 HAART effectively transformed HIV infection from a virtual death sentence into a manageable, chronic condition, reducing mortality rates by over $80 \%$ within two years of its introduction (Bhaskaran et al., 2008) ${ }^{6}$ Second, the introduction of HAART was unanticipated, providing a quasi-experiment that allows us to identify causal effects of a positive shock to health. Third, we observe an objective, timevarying, continuous measure of immune system health - the CD\& count, defined as the number of white blood cells per cubic millimeter of blood. Crucially, women participating in the study are informed of their CD4 count and can therefore respond to it. We exploit this to develop our identification strategy.

To identify causal effects of HAART on domestic violence and illicit drug use, we could simply compare HIV+ women before and after the introduction of HAART. However, this approach could confound the causal impact of HAART with other secular trends unrelated to the introduction of HAART. Instead, we estimate causal effects using differencesin-differences, comparing women with similar physical symptoms, but differences in their pre-HAART CD4 counts.7 Our treatment and control groups allow us to test our hypothesis that longer expected survival incentivizes costly upfront investments. This implies that

\footnotetext{
${ }^{4}$ In 2014, there were almost one million individuals with HIV in the United States, and about 230,000 were women (CDC, 2015).

${ }^{5}$ AIDS stands for Acquired Immunodeficiency Syndrome.

${ }^{6}$ Because of the effectiveness of HAART and the severity of HIV, the take-up of HAART was quite fast. For our sample of HIV+ women, over $55 \%$ had taken HAART within two years of the introduction and over $70 \%$ had within three years.

${ }^{7}$ An alternative approach would be to focus solely on women who actually use HAART, though medication choice is endogenous. In results available from the corresponding author, we show that HAART usage reduces violence if we use HAART introduction as an instrumental variable for HAART usage. One benefit of our approach is that we do not focus exclusively on users, so we can capture how introduction of HAART affected non-users through changes in expectations of future health induced by HAART introduction.
} 
HAART should lead to relatively large shifts in such investments among women with lower pre-HAART CD4 counts. Following this logic, our treatment group consists of HIV+ women who, prior to HAART introduction, exhibited CD4 counts low enough that medical guidelines suggest they commence treatment. Our control group consists of women with higher CD4 counts, whose immune systems had not yet begun to decline; these women faced longer pre-HAART expected survival and thus smaller HAART-induced increases in their expected survival. 8 A concern is that differences in CD4 counts between these two groups are endogenous. To address this concern, we omit women from our treatment group with CD4 counts that are so low that they might have already experienced the symptoms of compromised immune systems (AIDS). Omitting these women helps to ensure that women in the treatment group and control group are comparable: they are distinguished by a CD4 count cutoff, but are similar on other dimensions, including a lack of physical symptoms.

Both our identification strategy and the conceptual framework we develop to explain why HAART affected violence and drug use rely on the assumption that HAART affected behavior by shifting incentives to make costly investments with future payoffs. However, there is an important distinction between the two. Our identification strategy relies on the assumption that HAART affected the incentives and, hence, the behavior of sicker HIV+ women relatively more than healthier HIV+ women. This assumption motivates our focus on two groups of relatively similar women distinguished by a CD4 count cutoff. Our conceptual framework suggests that all HIV+ women potentially respond to HAART, including the healthier HIV+ women who comprise our control group, although they are predicted to respond less than the less healthy HIV+ women who comprise our treatment group.9 A drawback of our identification strategy is therefore that we potentially miss some portion of the true causal impact of HAART by including high-CD4 count women who were potentially

\footnotetext{
${ }^{8}$ Given how we construct them, an alternative description of the treatment and control groups might be the "Sooner Potential Benefit Group" and the "Later Potential Benefit Group," respectively. To avoid unnecessarily introducing new terminology, we use the terms "treatment" and "control" groups.

${ }^{9}$ Indeed, women who were not infected with HIV, but who faced a high risk of infection, could have responded to HAART if it improved expected health and survival conditional on becoming HIV+.
} 
"treated" by HAART in our control group. This implies that our estimates of the impact of HAART on domestic violence and drug use are likely to be biased downward, so we interpret them as lower bounds of true causal effects.

Using the identification strategy described above, we show that HAART led to reductions in domestic violence of roughly $15 \%$ for the treatment group relative to the control group. We also assess the effect of HAART on the use of illicit drug use, in particular, cocaine and heroin ${ }^{10}$ We show that the medical breakthrough we study led to decreases in illicit drug use of about 15-20\%. Our results are robust when considering domestic violence and the use of heroin. Our cocaine results are weaker and sensitive to the specification and therefore must be interpreted with caution. More broadly, and because we focus on women without symptoms, our findings provide support for the following claim: health innovations can affect people not only by making them feel better (e.g., by reducing their physical symptoms), but also by improving their expected future health, which incentivizes them to make costly investments. On this point, our work relates to Oster et al. (2013), who provide another example of how individuals' investments in their own human capital respond to new information about their future health even in the absence of discernible change in their immediate health.

After providing evidence that HAART introduction substantially reduced violence and illicit drug use, we turn to exploring mechanisms. First, we investigate whether HAART affected violence and drug use independently or affected one of these solely through its effect on the other. Though it is difficult to say definitively with the data we have, we provide some evidence that HAART affected both outcomes even after we control for the correlation between domestic violence and drug use via joint estimation.

Second, we examine whether our results are explained by contemporaneous changes in mental health (measured as depressive symptoms) or physical symptoms (measured as phys-

\footnotetext{
${ }^{10}$ We focus on these two drugs since they are frequently used by women in our sample. Cocaine includes both powdered and "crack" cocaine and belongs to a broader class of drugs known as stimulants. Another set of stimulants is methamphetamines, but less than $1 \%$ of women in our sample use it. Heroin is an opioid, a class that includes other drugs, such as oxycontin and illicit methadone, also used by few women in our sample. Our results are robust to including larger sets stimulants or opioids in our analysis.
} 
ical ailments, such as fever, night sweats and weightloss, associated with AIDS). While treatment group women exhibited relatively large increases in CD4 count, they did not experience relatively large improvements in their mental and physical health due to HAART. These findings show that the impacts of HAART we estimate on domestic violence and drug use are not attributable to immediate improvements in mental or physical health, but to better expected health and longer expected lifespans ${ }^{11}$

Third, we explore whether the effect of HAART on violence and drug use can be explained by changes in labor market outcomes. We show evidence of increases in employment among women in the treatment group relative to the control group after the introduction of HAART. Improvements in labor market outcomes are consistent with the view that HAART led to an upward shift in expected health, which in turn improved women's outcomes on a variety of dimensions, including violence, drug use and employment.

This study is the first to establish that actual or expected health improvements due to a medical innovation can reduce domestic violence. We find that interventions that improve women's health or otherwise augment their human capital can reduce both domestic violence and illicit drug use. The potential policy relevance of our findings is amplified by the fact that it is not always clear which policies most effectively reduce these behaviors. In the case of domestic violence, for example, there have been large declines over time, which are not yet fully understood (Black et al., 2011). Earlier work has suggested that increases in women's earnings relative to men's have contributed to this decline, which implies a role for women's labor market human capital (Aizer, 2010) 12 We are cautious about extrapolating our results to other types of health shocks since HIV is a specific chronic condition and the introduction of HAART was an unusually large and abrupt pharmaceutical innovation. However, the

\footnotetext{
${ }^{11}$ Findings are also in line with the logic behind our identification strategy that compares women with a similar lack of symptoms, but different underlying CD4 counts, which would suggest that HAART should have relatively larger effects on CD4 counts but not on symptoms.

${ }^{12}$ Other recent work, however, has shown evidence that increased compulsory education actually increased psychological violence in Turkey (Erten and Keskin, 2018). While puzzling, this result is consistent with Anderberg and Rainer (2013), who provide theory and evidence of a non-monotonic relationship between the wage gap and intra-partnership violence if an abusive man attempts to sabotage his partner's efforts to achieve labor market success when market conditions improve for women.
} 
introduction of HAART provides a unique opportunity to test whether a particular type of exogenous increase in health human capital could also play a role in reducing violence and illicit drug use.

The remainder of this paper is organized as follows: Section 2 introduces the data set used in this project and presents a preliminary data analysis. Section 3 discusses how we link health to domestic violence and illicit drug use, first conceptually and then empirically. Section 4 presents our main econometric results concerning the effect of HAART on violence and drug use. Section 5 examines some possible mechanisms explaining why better health reduces violence and drug use. These mechanisms include reductions in physical symptoms and depression and increases in employment. Section 6 speculates on the broader implications of our results and concludes.

\section{Data}

In this section, we introduce the data set we use in our analysis and discuss construction of our analytic sample.

\subsection{Data: The Women's Inter-Agency HIV Study}

We employ a unique data set from the Women's Interagency HIV Study (WIHS). The study was initiated to investigate the impact of HIV on women in the United States, and the sample was selected to include both HIV+ and uninfected or HIV-negative (henceforth: HIV-) women 13 Women in the WIHS study are predominately black and low-income and exhibit low levels of education. This reflects efforts to create a sample of women who are representative of women with HIV. Participants were recruited from a variety of venues, including: HIV primary care clinics, hospital-based programs, research programs, community outreach sites, women's support groups, drug rehabilitation programs, HIV testing sites and referrals

\footnotetext{
${ }^{13}$ Though not included in most of our analyses, HIV- women are examined for a test of validity.
} 
from enrolled participants (Barkan et al., 1998). The study began in 1994, and a second cohort was added to the sample in 2001-2002. Each woman in the sample was enrolled in one of six clinical consortia, located in: Bronx/Manhattan, New York; Washington, DC; San Francisco/Bay Area; Los Angeles/Southern California/Hawaii; Chicago, IL; and Brooklyn, New York. Semi-annual interviews are ongoing. Women were compensated for participation with monetary remuneration, gift packs, bathing and laundry facilities, meals, transportation and access to dental care at some sites. In addition, services such as HIV counseling, health assessments, health education and referral to clinical trials, primary care and social services were provided. For more information on the WIHS, see Barkan et al. $(1998){ }^{14}$

The WIHS data set is well-suited for use in assessing the causal effect of medical innovation on domestic violence and illicit drug use. First, because the WIHS started interviewing women in October 1994, before HAART became widely available in late 1996, we observe women before and after the unanticipated medical innovation and can compare women based upon their pre-treatment characteristics. For women in our main analysis, there were about four visits before the introduction of HAART. Second, there was an additional cohort added in 2001-2002, after the introduction of HAART. Although not included in our main sample, we use this additional cohort in a series of robustness checks to assess the potential effects

\footnotetext{
${ }^{14}$ Data in this manuscript were collected by the Women's Interagency HIV Study (WIHS). The contents of this publication are solely the responsibility of the authors and do not represent the official views of the National Institutes of Health (NIH). WIHS (Principal Investigators): UAB-MS WIHS (Michael Saag, Mirjam-Colette Kempf, and Deborah Konkle-Parker), U01-AI-103401; Atlanta WIHS (Ighovwerha Ofotokun and Gina Wingood), U01-AI-103408; Bronx WIHS (Kathryn Anastos), U01-AI-035004; Brooklyn WIHS (Howard Minkoff and Deborah Gustafson), U01-AI-031834; Chicago WIHS (Mardge Cohen), U01-AI-034993; Metropolitan Washington WIHS (Mary Young), U01-AI-034994; Miami WIHS (Margaret Fischl and Lisa Metsch), U01-AI-103397; UNC WIHS (Adaora Adimora), U01-AI-103390; Connie Wofsy Women's HIV Study, Northern California (Ruth Greenblatt, Bradley Aouizerat, and Phyllis Tien), U01-AI-034989; WIHS Data Management and Analysis Center (Stephen Gange and Elizabeth Golub), U01-AI-042590; Southern California WIHS (Alexandra Levine and Marek Nowicki), U01-HD-032632 (WIHS I - WIHS IV). The WIHS is funded primarily by the National Institute of Allergy and Infectious Diseases (NIAID), with additional co-funding from the Eunice Kennedy Shriver National Institute of Child Health and Human Development (NICHD), the National Cancer Institute (NCI), the National Institute on Drug Abuse (NIDA), and the National Institute on Mental Health (NIMH). Targeted supplemental funding for specific projects is also provided by the National Institute of Dental and Craniofacial Research (NIDCR), the National Institute on Alcohol Abuse and Alcoholism (NIAAA), the National Institute on Deafness and other Communication Disorders (NIDCD), and the NIH Office of Research on Women's Health. WIHS data collection is also supported by UL1-TR000004 (UCSF CTSA) and UL1-TR000454 (Atlanta CTSA).
} 
of participation in the study. Simply participating in WIHS can be beneficial to the participants, and we use the additional cohort to separate the effect of being a WIHS participant from the effect of medical innovation 15 Third, the data includes a rich set of behavioral, socio-demographic and health variables. Information is elicited on employment, income, housing, relationship and marital status, sexual behaviors, illicit drug use, and medication use 16

To quantify health, we use a standard measure of immune system functionality, CD4 count, defined as the number of white blood cells per $\mathrm{mm}^{3}$ of blood. CD4 count is measured using plasma samples, which are collected by medical professionals. Thus, the health measure that we use is objective rather than self-reported. Importantly, after each measure was taken, study participants were informed of their CD4 count. For healthy HIV - individuals, average CD4 counts range between 500 and 1,500. For HIV+ individuals, lower counts indicate that immune system deterioration has commenced, with counts below 200 signaling high susceptibility to common illnesses (a condition known as AIDS). Guidelines recommend starting HAART as CD4 counts decrease, generally once the CD4 count reaches 350 Mocroft and Lundgren, 2004, AIDSinfo, 2014). Monitoring CD4 cells allows individuals to track their immune system health, with lower CD4 reflecting a weaker immune system, sometimes known as immunosuppression. For example, a woman with a CD4 count of 400 is extremely unlikely to experience symptoms of immunosuppression, but because she has been told her CD4 count, she is likely to be aware that her immune system health has begun to decline and that her chances of long-run survival are therefore lower than those women whose CD4 count is still within the 500-1500 range typical among HIV- women.

Our measure of domestic violence indicates whether women reported experiencing any of three forms of violence in the six months prior to their interview: physical abuse, sexual abuse, or coercion by an intimate partner or spouse. These data are thus uniquely rich

\footnotetext{
${ }^{15}$ Results of this robustness check are discussed further in Section 4.3 .

${ }^{16}$ Although we observe whether the participants are in a relationship, we do not observe the length of the relationship.
} 
in including several forms of violence and not just one or two. We classify the woman as having experienced coercion if a partner threatened to hurt or kill her or prevented her from leaving or entering her home, seeing friends, making telephone calls, getting or keeping a job, continuing her education, or seeking medical attention. Moreover, we do not require that women report being in a relationship in order to report domestic violence. Indeed, many women report not being in a relationship at visits $t$ and $t+1$ and also report violence between the same two visits. This might occur if a woman has a short-term intimate partner who abuses her. Because we do not condition experiencing domestic violence on being in a relationship, we bypass problems that arise if HAART affected selection into a long-term partnership such as marriage or cohabitation.

\subsection{Construction of the Analytic Sample}

The main analytic sample includes all women from the first WIHS cohort who were HIV+ and answered questions about outcomes including domestic violence, illicit drug use and employment, as well as all of the controls that we include ${ }^{17}$ The first cohort of the WIHS data set includes 2,071 HIV + women who participated in the study for up to 33 visits, between October of 1994 and April of 2010. This amounts to 47,149 person-visits. Starting in the 10th visit, however, questions about domestic violence were only asked every other visit. Once we account for the change in timing of domestic violence questions, we are left with 2,065 individuals and 30,135 person-visits ${ }^{18}$ Second, we drop from our analytic sample 53 women who were in the study for just one visit before their death. Additionally, for women who died during the study period, the last "visit" is a record of their death; when we drop these "visits," we are left with 2,012 individuals and 29,492 person-visits. Third, we trim observations that are missing basic information such as date of visit, CD4 count before the

\footnotetext{
${ }^{17}$ See Section 4 for a list of controls.

${ }^{18}$ For outcomes that were asked every visit, we follow the same steps for trimming our data, but also include the odd numbered visits greater than ten.
} 
introduction of HAART, or age, leaving us with 23,215 observations from 1,995 individuals. ${ }^{19}$ Last, we trim observations that are missing information about domestic violence, drug use, employment, income or relationship status, leaving us with 13,948 person observations from 1,055 individuals ${ }^{20}$ Although we use an unbalanced panel, $73 \%$ of our sample stayed in the study for all 33 visits. ${ }^{21}$

A legitimate concern is the large number of missing observations. Reassuringly, we do not find evidence that observations are missing differentially for treatment versus control groups. To evaluate whether individuals are non-randomly missing from our sample, we perform two main tests. First, we show that demographics, being in the treatment group, and experiencing violence pre-HAART are not related to the likelihood of leaving the sample or the number of visits that one stays in the sample. We construct an indicator variable for ever leaving the sample and estimate logit regressions where the outcome is leaving the sample for any reason and explanatory variables are being in the treatment group, race, age, site of visit, and experiencing violence pre-HAART. No controls are significantly correlated with leaving the study. As a complementary test, we also regress the number of visits that the woman stayed in the study and find no evidence that any control variable is correlated with this outcome. Results from these estimates can be found in Appendix Table A1.

In our second test, we also regress an indicator variable for missing each outcome (domestic violence, cocaine use, heroin use, or employment) on race indicators, age, age squared, site indicators, logged CD4 count, and an interaction between the treatment group and logged CD4 count ${ }^{22}$ The coefficient of the interaction term between the treatment group and logged

\footnotetext{
${ }^{19}$ This large drop happens mainly because the date of the visit is missing. Date of visit is necessary because it indicates if HAART was available.

${ }^{20}$ When we impute missing variables, our results change very little. Thus, we choose to simply drop observations that are missing information.

${ }^{21}$ We include in our sample all women who are not missing information, including those who die during the study. In a conservative robustness check, discussed further in Section 4.3 , we re-run our analyses excluding all women who die early in the study and find that our results do not change for most specifications. Given these results, we do not believe that survival bias is driving our main empirical results. Excluding women who die is effectively non-randomly removing individuals from our sample, i.e., we may be removing women who are more likely to suffer domestic violence.

${ }^{22}$ To keep our sample size consistent, when CD4 count is missing, we impute the missing value and include
} 
CD4 count will tell us if women from the treatment group exhibit patterns of "missingness" that differ from the other women in the study. Women are included in this regression if they made the first three trims of the data as described above. We focus on this subsample because they are the women for whom we have information about basic sociodemographics. While we do find that women who are less healthy in terms of a lower CD4 count are more likely to be missing observations, as shown in Appendix Table A2, the actual changes in the probability of missing data for these outcomes are quite small. A 10\% increase in CD4 count decreases the probability of nonresponse by roughly 0.2 percentage points. Further, and more importantly, there is no difference between the treatment and control groups in terms of how CD4 count affects the probability of having a missing outcome. Thus, we find that, while health may affect the probability of an individual having a missing outcome, it does not do so differentially across our treatment and control groups.

\section{Conceptual Framework and Identification}

Both our conceptual framework and our identification strategy rely on the assumption that HAART shifted incentives to make investments with long-run payoffs. Still, it is important to distinguish between the two. Our conceptual framework implies that HAART shifted incentives for all HIV + women, including women with high pre-HAART CD4 counts who comprise our control group. Our identification strategy leverages the assumption that HAART shifted the incentives of women with low pre-HAART CD4 counts more than it shifted the incentives of those with high pre-HAART CD4 counts. Hence, pre-HAART CD4 counts did not govern whether women responded to HAART, but rather how much they responded. Section 3.1 discusses our conceptual framework and Section 3.2 our identification strategy. Section 3.3 presents summary statistics for our analytic sample, comparing the treatment to the control group, and discusses external validity. Finally, Section 3.4 provides evidence of the validity an indicator in the regressions for imputation. 
of our identification strategy.

\subsection{Conceptual Framework}

We begin with the premise that health is a form of human capital that not only extends life, but also improves well-being and increases productivity (Grossman, 1972). Women with different levels of health therefore face different incentives to avoid violence or drug use. Consider a woman in an abusive partnership or addicted to drugs. She could take a costly step, such as leaving her abusive partner or getting off drugs, reaping the benefits in the future. Since the costs of these actions are incurred in the present and the benefits accrue in the future, we treat these actions as investments. Longer expected lifespans mean women have a longer time to enjoy the benefits of these investments. Better health can also improve productivity, which might also mean that women are further incentivized to leave abusive partners or to stop using drugs so that they can return to work. In the context of HIV, HAART extended the life and improved the health of HIV + women who were using the treatment. We thus hypothesize that HAART, by improving expected health and longevity, would lead to lower levels of illicit drug use and domestic violence among HIV+ women.

A potential problem with this conceptual framework is that it presumes that women have some ability to control both violence and drug use. In the case of illicit drug use, addiction may mean that women are unable to change their behavior even in the face of a strong shift in incentives, such as a large positive health shock. Rooted in rational addiction (Becker and Murphy, 1988), we assume that women make rational choices regarding their drug use, weighing the benefits of continued use against the costs. This assumption is supported by clinical evidence showing that illicit drug use is responsive to shifts in incentives (Hart) et al. 2000) ${ }^{23}$ Robins (1993), who documented the rapid recovery from heroin addiction

\footnotetext{
${ }^{23}$ For example, Hart et al. (2000) report that regular cocaine users asked, in an experimental setting, to choose between cocaine and payments to be made several weeks later (and who have no other access to the drug until the following day) regularly opt for the delayed payment, especially when the amount of cocaine they forgo is fairly small.
} 
among Vietnam veterans upon their return home, provides earlier evidence in favor of control or agency in the context of addiction. One interpretation of her findings consistent with our conceptual framework is that these veterans faced stronger incentives to avoid heroin following a positive shock to their lifespan. Our assumption is also consistent with the idea of desisting, discussed in sociological literature, which describes reductions in (or avoidance of) risky behaviors after important life events, such as having children (Laub and Sampson, 2001). We hypothesize that HAART incentivized desisting from illicit drug use by endowing women with longer and healthier lives, thus making illicit drug use a relatively more costly option.

The application of our conceptual framework to domestic violence is more delicate. The assumption that women can "choose" to end abuse perpetrated by a violent partner can erroneously be perceived as "blaming the victim" for her own abuse. When relating domestic violence to human capital, we draw upon the resource theory of domestic violence. Often attributed to Gelles (1976), the claim is that women with more resources have better options outside of abusive partnerships and are therefore more likely to leave violent partners, which could incentivize the partner to be less violent. For example, if a woman's outside option is safe and comfortable, she is more likely to leave a violent partner. The resource theory of domestic violence helps to explain why women with higher education or income are more likely to avoid violence. The resource theory has been used to motivate bargaining theories of domestic violence. In bargaining models, women with better outside options have higher threat points. Because of this, they can credibly threaten to leave partners and therefore experience less violence. Resource and bargaining theories of domestic violence have been used to explain why no-fault divorce has reduced domestic violence (Stevenson and Wolfers, 2006), why cash transfers to poor women can reduce abuse (Bobonis et al., 2013; Angelucci, 2008; Pronyk et al., 2006), and why abuse is associated with poor labor market outcomes (Bowlus and Seitz, 2006; Anderberg and Rainer, 2013) and a larger gender wage gap (Aizer, 
2010) ${ }^{24}$ We take no position on intra-partnership bargaining. Rather, we argue simply that HAART improved health, increasing women's survival and human capital, and thus their incentives to leave, to threaten to leave or to avoid violent partners altogether.

Our conceptual framework makes no assumption about the relationship between violence and drug use even though they may be causally linked ${ }^{25}$ One possibility is that better health induces lower illicit drug use, which in turn reduces violence. This is plausible if drug use encourages violence, a possibility which has some support in medical literature, especially in the case of stimulants, such as cocaine (Phil and Peterson, 1993; Volavka, 2008). It is also plausible if women who reduce their drug use return to the labor market, which increases options outside of violent partnerships. Alternatively, less violence can lead to lower drug use, for example, if women who no longer suffer abuse are less prone to drug use as a coping mechanism (El-Bassel et al., 2005). It is also possible that health independently drives reductions in both drug use and violence. Though it is difficult to empirically disentangle all of these possibilities, we revisit them in Section 5, which provides a discussion of possible mechanisms underlying our key empirical findings. We now turn to a discussion of how we test the hypothesis that better health reduces domestic violence and illicit drug use.

\subsection{Identifying the Impact of Health on Violence and Drug Use}

Our aim is to identify how a marginal change in health affects an outcome of interest, such as domestic violence or illicit drug use. To illustrate, denote the propensity of the outcome

\footnotetext{
${ }^{24}$ Results reported in Alvira-Hammond et al. (2014) suggest that the relationship between labor market prospects and lower domestic violence extends to adolescents. Also related, but in a different medical context, Johnson and Pieters (2016) examine violence among women diagnosed with cancer. In our framework, a cancer diagnosis could be seen as a negative health shock, which could increase the likelihood that women experience violence. The authors focus on a different relationship, arguing that violence can affect health of women with cancer diagnoses by influencing how they seek treatment.

${ }^{25}$ Though they do not take a position on causality, Cohen et al. (2000) use the same data set we use to show that poorer women who use drugs are more likely to be abused. They describe this correlation as a "continuum of risk".
} 
of interest by $O$ and health as $H$. We aim to estimate:

$$
\frac{d O}{d H}
$$

To estimate this relationship, one possibility is to regress the outcome of interest onto a measure of health, such as CD4 count. Doing so, we face possible selection problems since health is potentially endogenous. Women in our sample who are in relatively poor health are likely to exhibit a number of other characteristics and behaviors, many of which are unobserved by the econometrician, and which are likely to affect domestic violence or illicit drug use. In fact, when we look at simple correlations using regression analysis, we find that the relationship between health and violence is complex and ambiguous. Table 1 shows a naive reduced form model for the full sample of HIV+ women ${ }^{26}$ Some relationships accord with our priors. For example, HIV + women with higher CD4 counts are less likely to use cocaine and are more likely to be employed. But, other relationships are not in accordance with our priors. For example, there is a no significant correlation between CD4 counts and domestic violence in the full sample. Further, there may be non-linearities in the relationship between health and violence, which complicate estimation of causal effects.

To explore this relationship further, we focus on women whose CD4 counts were observed to be below 200. A CD4 count this low suggests immunosuppression that characterizes AIDS. We compare these women before and after the first time they are observed with AIDS-level CD4 counts. We see that they are less likely to report almost every type of abuse when their CD4 counts are actually below 200, as shown in Table 2, In particular, $12 \%$ of women reported experiencing domestic violence on their last visit pre-AIDS diagnosis, compared to $9.5 \%$ post-AIDS diagnosis. This could mean that their illness has become so acute that they are not as likely to experience domestic violence. Further, women are also less likely to engage in illicit drug use after they exhibit AIDS-level CD4 counts. Heroin use falls from 20

\footnotetext{
${ }^{26}$ We also show that better health is associated with higher rates of employment, which is consistent with health as a form of human capital. We explore this point further in Section 5 .
} 
to $15 \%$ while cocaine use falls from 9.5 to $6.6 \%$. Given these non-monotonic patterns, all of which threaten the validity of comparing low-CD4 count women to healthier women, we do not include low-CD4 women in our treatment group.

A second possibility is to leverage an exogenous shift in health, such as an unanticipated medical innovation. One approach is to examine HIV+ women before and after HAART. A problem with this approach is that we cannot separate secular time trends or other contemporaneous shifts from the impact of HAART. For example, between 1993 and 2010, domestic violence was trending downward (Catalano, 2012).

To achieve identification, our approach exploits variation in health status at the time of HAART introduction along with the fact that HAART was an unanticipated innovation. The passage of time from the pre- to the post-HAART era affects our outcomes (domestic violence and illicit drug use) through the impact of HAART availability on health $(H)$ both directly and indirectly. For violence, this can be written as follows:

$$
\Delta V^{g}=\left[\Delta H^{g} \times{\frac{\partial V^{g}}{\partial H}}^{g}\right]+\left[\Delta X^{g} \times \frac{\partial V^{g}}{\partial X}\right]
$$

where $\Delta$ is the change in a variable from the pre-HAART to the post-HAART eras and $g$ indexes groups distinguished by pre-HAART health status (treatment and control groups, for example). The first term on the right-hand-side of equation (2) is the effect of HAART introduction on health (the health shock) multiplied by the effect of health on violence. The second term captures other avenues through which the passage of time between the pre- and post-HAART eras affected violence, including secular trends and omitted factors (together denoted $X$ ). For example the secular downward trend in domestic violence is captured in $X$.

To estimate the causal effect of HAART, we compute the difference-in-differences, relying on differences in how women respond to exogenous shifts in medical technology depending on their health status at the time of the innovation. We base our choice of control group on 
the assumption that women who have higher CD4 counts were affected by the introduction of HAART less than women who have lower CD4 counts because HAART was more urgently needed by those with lower CD4 counts. 27 Our treatment group consists of women who were beginning to exhibit HIV-induced immune system deterioration, which typically precedes full-blown AIDS, but who had not yet exhibited AIDS-level CD4 counts. These are women whose minimum CD4 count prior to HAART was between 300 and 399. As discussed above, the most basic current guidelines recommend beginning HAART when the CD4 count reaches 350, and our treatment group encompasses this number. However, since women in the treatment group have yet to reach CD4 counts where they would experience physical illness due to AIDS, they are more comparable to healthier women, whom we use as controls. The control group consists of women in relatively good health: HIV + women with high CD4 counts that never dipped below 400 prior to HAART introduction. Of those eligible to be included in our analysis, 166 women, with a total of 2,477 person-visits, are in the treatment group, and 269 women, with a total of 4,192 person-visits, are in the control group.

Relatively healthy HIV + women are a natural control group since, by virtue of a CD4count cutoff, they were not in imminent danger of becoming gravely ill at the time of HAART introduction. Our strategy identifies the effect of HAART by comparing the differential responses to HAART of women above and below the CD4 cutoff. However, because healthier women were likely to experience CD4 declines soon, they were also potential beneficiaries from HAART and may have also changed their behavior in response to the innovation. To the extent that healthier HIV + women also reacted to the introduction of HAART, using them as a control group leads us to under-estimate the effect of HAART.

Our identification strategy assumes that sicker women respond more strongly to HAART than healthier women. We explain this assumption in the case of domestic violence, but the explanation for illicit drug use is analogous. We envision women facing a dynamic tradeoff when deciding whether or not to avoid abuse. Avoiding abuse entails immediate

\footnotetext{
${ }^{27}$ If we repeat the analysis from Table 1 using the treatment group, we do find negative relationships between health and violence.
} 
upfront costs (e.g., leaving an abusive partner and potentially facing homelessness Zorza, 1991)), but also confers benefits in the form of lower abuse in the future. In this sense, avoiding abuse is similar to an investment with upfront costs and future benefits. Women with lower survival probabilities face a shorter expected lifespan and thus a shorter period during which to enjoy the returns from their investment. As a result, large increases in survival probability incentivize large shifts in costly behaviors with long-run payoffs. ${ }^{28}$ In response to HAART, women in the treatment group should experience large increases in survival probability relative to women in the control group for two reasons. First, medical guidelines regarding commencement of HAART mean that women in the control group are less likely to use it compared to women in the treatment group. Second, women in the treatment group are likely to experience increases in their survival probabilities sooner than those in the control group. HAART does not raise the survival probabilities of women in the treatment group above those of women in the control group, but simply raises them to the same level. Starting from a lower level and ending at the same level, the women in the treatment group experience a larger change in survival probabilities. This implies that women in the treatment group face larger HAART-induced shifts in incentives to make costly investments in their human capital compared to women in the control group and, hence, the effects would be larger for women in the treatment group.

\subsection{Descriptive Statistics}

Before assessing the validity of our approach, we present summary statistics for the treatment and control groups. We also discuss how the women in our sample compare to other women in the U.S., including HIV + women, a comparison that is important when assessing the external validity of our results. Table 3 provides summary statistics for our treatment group and control group in Columns 1 and 2. In Column 3, we test that the means are equal across

\footnotetext{
${ }^{28} \mathrm{~A}$ key result of human capital theory is that higher life expectancy incentivize further investments in labor market human capital (see e.g., Ben-Porath (1967)). This theory has broad empirical support (Black et al. 2007; Jayachandran and Lleras-Muney, 2009; Oster et al., 2013, Yi et al., 2015).
} 
the treatment and control groups.

\subsubsection{Treatment vs Control Group}

According to Table 3, treatment and control groups are quite similar in terms of demographics, including race and education, and pre-HAART characteristics such as risky behaviors, symptoms, and experience with violence. About $67 \%$ of the treatment group is black, $20 \%$ is Hispanic, and $12 \%$ is non-Hispanic white (henceforth simply white). This is roughly equivalent to the control group, where these percents are 64, 22, and 12 respectively. Our samples are also similar in terms of education: $30 \%$ of each group graduated high school, $22-23 \%$ attended some college, and $10 \%$ of the treatment group and $7 \%$ of the control group graduated college. Pre-HAART incomes are also comparable across groups. While the high CD4 count women were somewhat more likely to have been employed (43\% vs 38\%) and less likely to have been married prior to the introduction of HAART (32\% vs $25 \%$ ) we cannot reject the null hypothesis that the means are equal.

Overall rates of violence pre-HAART are similar across the treatment and control groups. In particular, $27 \%$ of the treatment group experienced domestic violence before the introduction of HAART compared to $34 \%$ of the women in the control group. Women in the control group were more likely to suffer sexual abuse, physical abuse, and coercion than our treatment subsample, but the only significantly different form of abuse is sexual abuse. Turning to illicit drug use, we find that, prior to the introduction of HAART, $28 \%$ of the treatment group had used cocaine, compared to $31 \%$ of women in the control group. Heroin use prior to HAART was very similar between the two groups: $18 \%$ for the treatment group and $16 \%$ for the control group. Mean differences in outcomes between the groups do not threaten the validity of using difference-in-differences approach to estimating causal effects as long as the trends in domestic violence and other outcomes are similar. We discuss the parallel trends of our main outcomes in the following subsection. 


\subsubsection{External Validity}

Our sample is quite similar to the statistics that the CDC reports about the HIV+ population of women living in the United States and, hence, is an appropriate starting point for studying links between health, domestic violence and illicit drug use. The majority of women in our sample are low-income, under-employed, and non-white - socio-demographic groups most likely to experience domestic violence and use illicit drugs ${ }^{29}$ For example, it is estimated that of the total number of women living with diagnosed HIV, 61\% are black (CDC, 2015), compared to about $65 \%$ for our sample. Additionally, in a sample of individuals living in high poverty areas, the CDC found that the likelihood of being HIV+ was negatively associated with completed education and income (Denning and DiNenno, 2010), which we also observe in our sample. Drug statistics for our sample are also more similar to those exhibited by HIV+ women than to U.S. women in general. The National Survey on Drug Use and Health found that about $16 \%$ of individuals who had been diagnosed with HIV reported using an intravenous drug in their lifetime, which is extremely close to the $17 \%$ reported by our sample.

Finally, in our main analyses, we present results separately for black women. The black women in our sample have, on average, less education than the white women. They also come from less well-off households: $49 \%$ had maximal pre-HAART incomes below $\$ 12,000$ compared to $25 \%$ of white women. Black women are more likely than white women to report domestic violence. Lifetime prevalences of rape, physical violence, and/or stalking are estimated to be $43.7 \%$ for black women and $34.6 \%$ for white women (Black et al., 2011). Black women also suffer domestic violence at higher rates than the white women in our sample: $30 \%$ of black women reported experiencing domestic violence between one year prior to the start of the survey and the introduction of HAART, compared to $23 \%$ of white women. Patterns of drug use by black women in our sample compared to other women

\footnotetext{
${ }^{29}$ For example, high school completion rates are about $80 \%$ for females in the United States Heckman and LaFontaine, 2010), compared to about $60 \%$ for our full sample.
} 
are more nuanced. For example, $28 \%$ of black women reported having used cocaine (either crack or powdered) prior to the introduction of HAART, compared to $23 \%$ of white women. However, $12 \%$ of the black women in the sample reported having used heroin during this time period, compared to $17 \%$ of the white women.

\subsection{Research Design and Internal Validity}

In this section, we discuss our empirical approach to estimating causal effects. Identification using the difference-in-differences approach requires that the path of the outcome variables for the treatment group and the control group would not be systematically different in the absence of HAART introduction. Specifically, this means that the introduction of HAART should be the only factor that drove the treatment group to experience a change in an outcome variable, such as domestic violence, relative to the control group. To confirm this, we study pre-HAART trends in our outcome variables and show that they are not different for our treatment group and our control group.

The validity of our research design relies on HAART being an unanticipated innovation. For evidence of this within our sample, we turn to questions used to compute the CES-D scale, which is used to asses whether women are likely to be depressed 30 One question asks whether respondents were hopeful about the future in the week leading up to their interview. We consider the probability that women in the sample answered "most or all of the time" to this question, and plot this before and after the introduction of HAART in Figure 1. There are two reasons why this figure suggests that HAART was not anticipated. First, before the introduction of HAART, the percentage of HIV+ women who reported being hopeful was relatively flat. They experienced a jump in hopefulness right at the introduction of HAART. If they had anticipated HAART, they might have reported more hopefulness earlier. Second, HIV - women did not experience such a jump. If some other factor drove the increase in

\footnotetext{
${ }^{30}$ CES-D is a depression screening test and stands for the Center for Epidemiological Studies Depression scale. See Ostrow et al. (1989) or Detels et al. (2001) for use of the CES-D scale score data in the context of an HIV study.
} 
hopefulness, then this would be reflected by a jump in the hopefulness of HIV- women.

Next, we discuss pre-HAART trends among our treatment and control group. In Figure 2. we plot the pre-HAART trends in domestic violence (Panel 2a), cocaine use (Panel 2b), and heroin use (Panel 2c) for the treatment group and the control group. The plots show that trends for the treatment group and the control group were comparable prior to the introduction of HAART, which suggests that HAART is the driving force in the difference in outcomes. We also exploit the fact that we have multiple periods prior to the introduction of HAART to conduct a formal test of whether there are differences in trends between the treatment and control groups. For each outcome, we estimate the following models:

$$
O_{i t+1}=\text { Treatment }_{i} \delta+D_{t} \alpha_{t}+\sum_{t=-3}^{t=28} \text { Treatment }_{i} \times D_{t} \gamma_{t}+X_{i t} \beta+\epsilon_{i t}
$$

where $O_{i t+1}$ is the outcome of interest (domestic violence, cocaine use, or heroin use) and $D_{t}$ is an indicator for the date of visit bin such that $D_{0}$ is the last period before HAART was introduced. Each bin is a six month period, and HAART is not available in the bins -3 through 0. $X_{i t}$ is a vector of controls, including age at visit, age squared, indicators for race, and indicators for site of visit. For each model, we test for pairwise parallel preHAART trends. Specifically, we test the null hypothesis that coefficients $\gamma_{-3}$ through $\gamma_{0}$ are equal. This essentially tests that the trends in outcomes prior to HAART are parallel. In Table 4, we show that we cannot reject the null hypothesis that the coefficients are equal for both domestic violence and heroin use, suggesting that there is no difference in preHAART trends for these outcomes. For cocaine use, we estimate a p-value of 0.091, which is a borderline significant value. This suggests possible mean reversion, which could lead to an over-estimation of causal effects, so we must interpret our estimates with caution. Additionally, we test whether the pre-treatment trends in domestic violence, cocaine use, and heroin use are not jointly significant, and fail to reject the null hypothesis that there is no difference in trends $(\mathrm{p}=0.148)$. As we explain below, the $\mathrm{p}$-value is 0.19 when we account 
for differences in observables using inverse probability weighting.

In a related exercise, we plot the residuals from a probit model that regresses domestic violence on age, age squared, age cubed, race dummies, and site dummies. As shown in Figure 3, there is a clear break between the treatment group and the control group after the introduction of HAART, indicating that the introduction of HAART affected the two groups differently.

We also conduct an event study to investigate whether pre-HAART trends are driving our results. Figure A1 in Appendix A shows the coefficient of the interaction for the periods before and after the introduction of HAART. Because there are so many more periods after HAART was introduced than before (16 versus 4 for domestic violence), we combine the post-HAART periods in this exercise. Periods prior to HAART introduction are one year in length, and periods after HAART was introduced are five years. For each outcome, we expect that coefficients on dummies for periods -2 and -1 (the periods prior to HAART) should not be significant and negative, because if this were the case, then declines in violence or drug use for the treatment group would have begun prior to the introduction of HAART. For domestic violence and heroin use, we find no difference in pre-HAART trends between the treatment group and the control group. For cocaine use, we find that the treatment group did exhibit a rising trend (relative to the control group) prior to HAART. This rise, however, is opposite to the direction we observe after HAART, which is reassuring because it suggests that post-HAART changes are not driven by trends beginning prior to HAART.

Finally, we discuss two additional concerns that might threaten the validity of our research design. First, one might be worried that another shift (e.g., a government program or policy change) had an impact on the treatment group, but not on the control group (or vice-versa). An obvious candidate is the Personal Responsibility and Work Opportunity Reconciliation Act (PRWORA), which reformed welfare and was signed into law in August of 1996, just as HAART was introduced. However, given that the treatment and control groups have similar socio-demographic characteristics, including income and education, it is unlikely that welfare 
reform affected the control group differently than the treatment group ${ }^{31}$ A second concern might be that domestic violence is drastically under-reported. By some measures, $50 \%$ of violent episodes go unreported (Greenfeld et al., 1998). However, this would affect our results only if there were a shift in under-reporting that differentially affected the treatment group and the control group and, moreover, if this shift coincided with the introduction of HAART. Though we cannot rule out this possibility, we believe that it is unlikely.

\section{Main Results}

In this section, we present our main results. We show that the treatment group experienced reductions in domestic violence and illicit drug use that the control group did not. We also perform several robustness checks, showing that our results are not driven by survival bias and are robust to estimation using propensity score matching.

\subsection{Health and Domestic Violence}

To test if the treatment group experienced a reduction in domestic violence after the introduction of HAART, we use a difference-in-differences approach. We estimate probit models where the dependent variable is an indicator of whether a woman experienced domestic violence since her last visit using the following specification:

$$
V_{i t+1}=H A A R T_{t} \alpha+\text { Treatment }_{i} \delta+H A A R T_{t} \times \text { Treatment }_{i} \gamma+X_{i t} \beta+\epsilon_{i t}
$$

where $V_{i t+1}$ indicates if the woman reported violence at $t+1$, which she experienced between periods $t$ and $t+1$. $H A A R T_{t}$ is an indicator variable for HAART being available at time

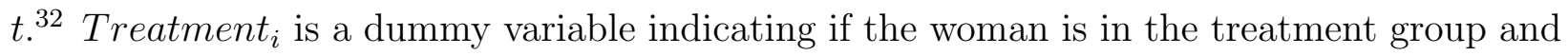

\footnotetext{
${ }^{31}$ Unfortunately, we cannot test this assumption more directly since our data only contain information about welfare participation after the introduction of HAART.

${ }^{32}$ We use lagged HAART availability to account for the fact that domestic violence and other outcomes are measured since the last visit. For example, consider visits that occurred in September of 1996, right
} 
$X_{i t}$ is a vector of individual $i$ 's characteristics at time $t$ and includes basic controls: age, age squared, and age cubed at time $t$, as well as indicator variables for race and site of study ${ }^{33}$ The coefficient of interest is $\gamma$, which indicates if the treatment group responded differently to the introduction of HAART than the control group. To control for serial correlation, all specifications are clustered at the individual level (Bertrand et al., 2004).

We report findings in two tables. Table 5 shows the estimated coefficients from the probit models, while Table 6 presents the marginal effects of the interaction term, which is the parameter of interest. We follow Puhani (2012) in calculating marginal effects of the interaction term ${ }^{34}$ In each table, findings for domestic violence are shown in the first two columns. We show two specifications for both our main sample and the sample consisting of only black women. Column 1 (and all odd columns) includes the interaction but no other controls, and Column 2 (even columns) includes the basic controls described above.

The first row of Table 5 shows that HAART availability is associated with a decline in domestic violence. This is consistent with secular declines in domestic violence during this time period (Catalano, 2012). Turning to difference-in-differences estimates, we find that the treatment group experienced a decrease in domestic violence that otherwise similar women in the control group did not. According to Table 6, which reports marginal effects, the relative decline was between 1.5-1.7 percentage points, depending on the specification. To put this number into context, if we divide it by the pre-HAART treatment group mean of $13 \%$ (shown in the table), it implies a $14-16 \%$ decline ${ }^{35}$

around the time when HAART was introduced. At this visit, women were asked about violence that they had experienced in the last six months, roughly the time since their previous visit. However, HAART was not available to them during this time period and therefore they would not have experienced any benefits of this medical innovation.

${ }^{33}$ We could also control for other demographic characteristics and reported behaviors, such as relationship status, income, and drug use. However, these variables may measure mechanisms through which HAART affects our outcomes of interest, so we omit them from our specifications. In results available from the corresponding author, we show that main results are robust to the inclusion of these additional variables.

${ }^{34}$ Following Puhani (2012), Karaca-Mandic et al. (2012) also show how to calculate standard errors in the same manner.

${ }^{35}$ To further contextualize the magnitude of estimated marginal effects, $27 \%$ of women in the treatment group report experiencing domestic violence at least once prior to HAART. A 1.5 percentage point decline is roughly $6 \%$ of this number. We could also compare estimated marginal effects to the full sample mean of 
When we restrict the sample to black women, we find similar results. Black women in the treatment group experienced a decline in domestic violence between 2.1-2.4 percentage points as compared to black women in the control group. This implies a decrease in violence of between 16 and $18 \% 36$

In assessing the magnitude of these declines, it is difficult to find research that links medical innovation and domestic violence. Research on policy interventions have yielded mixed results. For example, Heaton (2012) finds that Sunday liquor laws have no effect on domestic violence, while Iyengar (2009) reports that mandatory domestic violence arrest laws actually lead to an increase in intimate partner homicides. More closely related to our study are changes to women's earnings, both absolutely and relative to men's. For example, Aizer (2010), shows that reductions in violence of about $9 \%$ are explained by a 20 -year decline in the male-to-female wage gap. In a recent paper, Cesur and Sabia (2016) show that combat veterans are between three and six percentage points more likely to be violent than veterans who were not assigned to combat zones 37

the outcome variable (also presented in results tables). In the case of domestic violence the full sample mean is smaller than the pre-HAART treatment group mean, so that estimated marginal effects would imply a larger percent change. When presenting our remaining results using differences-in-differences, we continue to divide estimated marginal effects by pre-HAART treatment group means. For guidance on this, Mayer et al. (2014) also estimate differences-in-differences probit models and contextualize the magnitude of estimated marginal effects by comparing them to pre-treatment treatment-group means.

${ }^{36}$ As discussed in Section 2, black women suffered domestic violence at higher rates than other women in the sample. For ease of exposition, we run separate regressions for black women in our sample. However, in a separate analysis, we consider heterogeneous effects and re-estimate equation (4) including an interaction between black, HAART availability, and an indicator for being in the treatment group. Although the coefficient on the triple interaction is negative, it is not statistically significant, as shown in Appendix Table A3. Thus, we cannot rule out that declines for non-black women in our sample were of the same magnitude as declines for black women. We only show probit coefficients because of the difficulty interpreting marginal effects of a triple interaction.

${ }^{37}$ Alternatively, one can look at the effect of conditional cash transfer programs, such as Progresa or Oportunidades. Among poor Mexican women, Angelucci (2008) shows relatively modest declines in domestic violence, some of which can be explained by lower alcohol usage among transfer recipients. On the high end in terms of the magnitude of causal effects, Bobonis et al. (2013) report that recipiency of a conditional cash transfer targeting women is associated with a decrease in domestic violence of about $40 \%$. The authors consider data from Oportunidades, a Mexican program, which offers substantial cash transfers to families whose children are in school that amount to about $10 \%$ of their average monthly expenditures. We should note that our results are somewhat difficult to compare since they also find an increase in intimidation and threats, which may be evidence of substitution among different forms of abuse. In contrast, we find evidence that all forms of abuse, including coercion, decreased. These results are available upon request from the corresponding author. 


\subsection{Drug Use}

Next, we analyze how the introduction of HAART affected use of cocaine and heroin. As with domestic violence, we estimate models of the following form:

$$
B_{i t+1}=H A A R T_{t} \alpha^{B}+\text { Treatment }_{i} \delta^{B}+H A A R T_{t} \times \text { Treatment }_{i} \gamma^{B}+X_{i t} \beta^{B}+\epsilon_{i t}^{B},
$$

where $B_{i t+1}$ refers to individual $i$ 's behavior (i.e., use of cocaine or heroin) reported at time $t+1$. Again, $H A A R T_{t}$ is an indicator for HAART availability at time $t$ and Treatment $_{i}$ indicates if individual $i$ is in the treatment group. $X_{i t}$ includes the basic controls discussed above: age, age squared, age cubed, race and site indicators.

We find limited evidence that the treatment group decreased their use of cocaine compared to the control group. In Table 5 (Columns 3 and 4), we show probit coefficients and in Table 6, we show marginal effects from the interaction term $\gamma^{B}$ from equation (5). We find that the interaction term is statistically significant only under the most basic specification. In this specification, we find a decrease in cocaine use of 2.9 percentage points, or about $16 \%$ starting from the pre-HAART treatment group mean of $17.8 \%$ Although $\gamma^{B}$ is always negative when we restrict the sample to black women, we cannot rule out the possibility that there is no effect.

We find that the treatment group also decreased their use of heroin compared to the high CD4 count HIV+ women. The results, shown in Table 6] (Columns 5 and 6), are robust and the average effects are always significant at least at the $5 \%$ level. We find that heroin use decreased by 1.9-2.2 percentage points, or 22-25\% when compared to the pre-HAART treatment group mean of $8.7 \%$. However, when we restrict the sample to only include black women, we find that the decrease is only significant in the most basic specification.

Contextualizing our results is again challenging, in part because of the lack of findings on how policy affects drug use. The WIHS is very unusual in that it asks about illicit drug use

over time. One related study, Corman et al. (2013), examines the effect of welfare reform 
on the drug use of women who are at risk of being on welfare. They find that self-reported illicit drug use in the past year (excluding marijuana) fell by about $18 \%$ after welfare reform, which changed work incentives for women.

\subsection{Robustness Checks}

In this section, we discuss two robustness checks. First, we test whether survival bias is driving our results. To do this, we restrict our sample to women who were in the study for at least 15 visits, which is about 7.5 years, and then repeat our main analyses using equations (4) and (5). Results are reported in Appendix Table A4, which shows marginal effects of our main findings with the restricted sample. We find that restricting the sample in this manner does not affect our results. If anything, our findings on drug use are stronger ${ }^{38}$

The second robustness check that we perform uses propensity score matching. Following Imbens (2015), we construct normalized differences of our covariates in order to investigate the overlap between our treatment and control groups. To test whether baseline characteristics are similar between groups, Imbens (2015) suggests a rule of thumb that normalized differences be below 0.25 . The majority of our coefficients are below 0.1, as shown in Appendix Table A5, which provides some evidence that the treatment and control group are comparable. Appendix Figure A2 shows that the propensity scores for the treatment group and the control group have substantial overlap 39 Looking at the figure, the average of the estimated propensity score is lower for the treatment group, which indicates that the two groups are not comparable, except after appropriate reweighing of the observations. We thus repeat our main analyses using inverse probability weights. Similar to our main specification checks, we jointly test that the pre-HAART trends in domestic violence, cocaine use, and

\footnotetext{
${ }^{38}$ Even when we exclude women who died or left the study early, our main findings remain. About $95 \%$ of our sample stayed in the study for at least this period of time. In another test, we show that our results are not driven by simply participating in the WIHS study. We accomplish this by comparing violence and drug use trajectories for women in our analytic sample versus women in the second cohort who entered the sample after HAART was introduced. Results from these analyses are available from the corresponding author.

${ }^{39}$ We do not present figures from other outcomes, as they are very similar. However, these are available upon request from the corresponding author.
} 
heroin use are different and fail to reject the null hypothesis when using the inverse probability weights $(\mathrm{p}=0.19)$. Thus, even when considering weighting by the inverse probability of being in the treatment group, there is little evidence that pre-HAART trends differed between the treatment and control groups. Turning to the main analysis, we find that there are no differences between the treatment group and the control group pre-HAART, as shown in Appendix Table A6. However, after the introduction of HAART, violence and heroin use fell for the treatment group compared to the control group. These findings are similar to those from our main difference-in-differences specifications.

\section{Mechanisms}

In this section, we further explore possible mechanisms explaining why health improvements lowered domestic violence and illicit drug use. Section 5.1 considers the roles of both physical and mental health improvements. Section 5.2 examines the relationship between illicit drug use and violence. Section 5.3 studies potential HAART-induced improvements in labor market outcomes and whether they play a role in explaining our main estimates.

\subsection{Physical and Mental Health Improvements}

We now consider physical health and mental health, which are two alternative mechanisms which could help to explain our findings. Starting with physical health, we begin by documenting that women in the treatment group experienced large increases in their immune system health (CD4 count) compared to our control group. In particular, in Table 7, we return to our difference-in-differences framework to show relative increases in CD4 count among women in the treatment group after HAART. This improvement in underlying health may have translated to improvements in how women felt after HAART, which might lead to declines in domestic violence or illicit drug use. In Table 8 (Columns 3 and 4), we assess whether women in the treatment group exhibit shifts relative to the control group in 
the probability of experiencing at least one symptom, where the symptoms we consider are: fever, memory problems, numbness, weight loss, mental confusion, and night sweats. We again return to the original difference-in-differences framework ${ }_{40}^{40}$ We find little evidence of post-HAART relative declines in reporting at least one of these symptoms for women in the treatment group after HAART ${ }^{41}$ This absence of changes in symptoms is not surprising since the women we study are unlikely to have experienced symptoms attributable to HIV prior to HAART introduction 42

That is, women simply feeling better, measured by a lack of physical symptoms, does not appear to be an important mechanism generating our main results. ${ }^{43}$ Instead, HAART is an example of a medical innovation that affected behavior without affecting physical symptoms. Recall, women in the treatment group, despite lower CD4 counts at the time of HAART introduction, had yet to experience the symptoms of AIDS. Hence, HAARTinduced reductions in domestic violence and illicit drug use do not appear to be driven by contemporaneous improvements in how they feel as measured by physical symptoms. Instead, our findings on symptoms suggest that much of the role of HAART in affecting violence and drug use operated through its effect on expectations of future physical health and survival.

Another possible mechanism is mental health. It might be the case that a positive shock in expected health due to the arrival of a new medical technology leads to better mental health. If so, women may perceive better options outside of violent partnerships and refrain from illicit drug use ${ }^{44}$ In Table 8 (Columns 1 and 2), we use the same difference-in-differences

\footnotetext{
${ }^{40}$ For consistency with the CES-D Score, we use OLS specifications. However, in results available upon request, we also tried the probit specifications and found no difference.

${ }^{41}$ We also tested individual symptoms along with the total the number of symptoms using a Poisson count and found no difference between the treatment and control group.

${ }^{42}$ Even if they had, HAART side effects may have simply replaced symptoms, leaving women feeling no better than before HAART In related work, Papageorge (2016) shows that HAART side effects among HIV+ men replaced some of the symptoms of HIV, though this occurred among sicker patients that are not the focus of this study.

${ }^{43}$ However, it is worth reiterating that these results bolster the argument that women in the treatment group are comparable to those in the control group in that, despite having lower CD4 counts, they do not exhibit physical symptoms of AIDS prior to the introduction to HAART.

${ }^{44} \mathrm{~A}$ correlation between depressive symptoms and exposure to violence is reported in Johnson et al. (2014),
} 
framework as in our main analysis to study depression as the outcome variable. To measure depression, we use the CES-D Score and find little evidence that mental health can explain the links between HAART introduction and domestic violence or illicit drug use 45 Again, our results suggest that contemporaneous changes to physical or mental health after HAART do not explain the impact of HAART on violence and drug use.

\subsection{Relating Drug Use and Violence}

Our finding that HAART reduced both violence and drug use is consistent with several possible mechanisms. One possibility is that HAART affected both independently. Another is that HAART only affected violence through its impact on drug use. One hypothesis is that by lowering drug use, violence mechanically declined. Alternatively, HAART may have reduced violence, leading women to avoid drugs, perhaps experiencing less need for drugs to cope with violence. Although it is difficult to distinguish between these possibilities given available data, we believe that we can make some progress on the question.

First, we allow violence and drug use to be jointly determined. In effect, doing so controls for the correlation between violence and drug use. We show that our basic results are qualitatively similar even when we control for this correlation. ${ }^{46}$ Even when we control for the correlation between the two outcomes, HAART appears to have independent effects on domestic violence and illicit drug use. In other words, neither one is simply a by-product of the other 47

Second, we exploit the fact that heroin and cocaine appear to have different relationships

albeit among adolescents. A related view is that lower illicit drug use can improve mental health, which previous research has shown can lead to declines in violence (Devries et al., 2013).

${ }^{45}$ In results available upon request from the corresponding author, we show that controlling for mental health does not change our main results. We also show that our main findings are not driven by increased interaction with the medical community after HAART was introduced.

${ }^{46}$ Results are shown in Appendix Tables A7 (cocaine use) and A8 (heroin use).

${ }^{47} \mathrm{It}$ is worth mentioning that results on joint estimation are not robustness tests of main results. Rather, they serve to examine whether HAART had effects on two different outcomes once we have controlled for correlation among the two outcomes (versus, for example, having a direct effect on one outcome that affects the other). 
with abuse. In Table 9, we present results from a regression of violence on drug use, income, employment, and our usual set of controls. We instrument heroin and cocaine use with previous period drug use in order to avoid capturing drug use as a response to domestic violence (e.g., using drugs as a coping mechanism). Importantly, we distinguish between heroin use and cocaine use. We find that, whereas use of cocaine is associated with more violence, use of heroin is associated with less violence. This result is consistent with the medical literature that studies the impact of drug use on violence and finds that heroin has a pacifying or sedating effect on users ${ }^{48}$ The negative coefficient on heroin use strengthens the argument that HAART had independent effects on both violence and drug use. The reasoning is as follows. Suppose HAART only affected heroin use and had no impact on violence except through its correlation with heroin use. Then, we might expect violence to rise if heroin use went down. Instead, both decline. Though this evidence is somewhat speculative, these empirical patterns are consistent with the claim that HAART had independent effects on violence and illicit drug use.

\subsection{Employment and Income}

Thus far, we have shown that HAART reduced both domestic violence and illicit drug use. Moreover, though intuitively appealing, the idea that direct physical and mental health improvements (measured by physical symptoms and the CES-D measure of depression) led to declines in domestic violence and illicit drug use is not borne out by our data. In this section, we consider changes to labor market outcomes induced by HAART. Our hypothesis is that improved labor market prospects might help to explain why women perceive better options outside of violent partnerships or face stronger incentives to desist from drug use. Further, our conceptual framework envisions health as a form of human capital and that

\footnotetext{
${ }^{48}$ See Boles and Miotto (2003) or Volavka $(2008)$ on pharmacologically-induced violence. For the effects of heroin, see, in particular, Jaffe and Jaffe (1999). An underlying and important assumption in relating illicit drug use to domestic violence is that intimate partners are likely to use the same drugs. This assumption has broad empirical support from a variety of fields. See, for example, Anglin et al. (1987). Vanyukov et al. (1996) provide a review of this literature.
} 
implies that women with more human capital are less likely to experience abuse or to use illicit drugs. Evidence of HAART-induced improvements in labor market outcomes supports the treatment of health as a form of human capital.

To assess HAART-induced differences in labor market outcomes, we return to our differencein-differences framework. We treat employment at the time of visit as the labor market outcome of interest. The marginal effects are presented in Table 10. Estimates show that the treatment group became relatively more likely to be employed after HAART. Black women in the treatment group became much more likely to be employed relative to black women in the control group for all of our specifications. This amounts to an increase in the probability of employment for the treatment group of about 4.8-5.5 percentage points, or about 19-22\%, for the full sample and 7.7-8.1 percentage points, or about 35\%, for the black women subsample. Pre-HAART treatment group means are $25.3 \%$ for the full sample and $22.3 \%$ for the black sample.

Our findings on employment are broadly consistent with those in Goldman and Bao (2004), who also study HAART and employment. They show that HAART use increased the probability that HIV+ individuals kept working by $37 \%$. Our results are smaller for at least two reasons. First, we do not condition on HAART use as they do but instead rely on HAART introduction (similar to an intent-to-treat analysis). Second, their finding conditions on working at the time of HAART introduction while ours does not. Indeed, individuals in our sample are not highly educated and do not exhibit strong ties to the labor market before the introduction of HAART. Perhaps more comparable to our setting, Goldman and Bao (2004) find no effect of HAART on the likelihood of returning to work, conditional on not working prior to HAART introduction. Compared to their estimates for non-workers, our findings on employment are relatively large 49

\footnotetext{
${ }^{49}$ Our results on employment are broadly consistent with literature considering how HAART affected labor market outcomes in developing countries in Africa. For example, Thirumurthy et al. (2008) find that antiretroviral therapy is associated with an increased attachment to the labor force, in terms of both participation and hours, for patients in western Kenya. Habyarimana et al. (2010) document patterns of absenteeism in Botswana and provide evidence that an increase in CD4 count decreases illness-related absence
} 
Though our results on labor market outcomes provide evidence that HAART increased women's labor market human capital, the precise mechanism is difficult to identify. We find that women with better labor market prospects are more likely to avoid abusive partnerships. Using individual fixed effects, we find that income and employment are associated with lower rates of violence. We show this using a linear probability model in which we regress domestic violence on employment in the same period, income, various sets of sociodemographic variables, and individual fixed effects. In the final specification with the largest set of controls, including health, socio-demographic characteristics and risky behaviors, we find (see Table 11) that being employed lowers the likelihood of being abused by 0.8 percentage points.

We also find that drug use and violence are negatively correlated with employment among women in our sample 50 However, there are several mechanisms that could explain why HAART would lower drug use and violence and also have an effect on employment and income. For example, reductions in violence and drug use would presumably make working easier. Alternatively, improvements to expected health could lead women to expect better labor market prospects, giving them stronger incentives to leave or avoid abusive partners and causing them to view drug use as more costly. Even further, if HAART improves labor market prospects, it could incentivize further investments in human capital. In the case of poor women with HIV, avoiding drug use could therefore be seen as an investment in future earnings (Becker and Murphy, 1988). Given the data we have, we are unable to distinguish among these mechanisms; indeed, it is possible that each of them plays a role. However, our findings on labor market outcomes support the conceptual framework we have proposed. HAART improved women's lives on a number of dimensions, reducing domestic violence and illicit drug use and improving their labor market prospects.

from work.

${ }^{50}$ These results are shown in Appendix A. Tables A9 and A10 


\section{Conclusion}

We have presented evidence that HAART lowered domestic violence by about $15 \%$ and reduced illicit drug use by 15-20\% among a group of low-income, predominantly black, HIV+ women. The fact that HAART marked a massive improvement over previous HIV treatments, together with the seriousness of HIV, enables us to detect subtle effects of this pharmaceutical innovation on domestic violence and illicit drug use. The underlying mechanism is that this new medical technology constituted a positive health shock, improving women's health trajectories and, hence, increasing their human capital.

How far our results generalize to other groups, to negative health shocks, to other chronic illnesses and to behaviors other than domestic violence and drug use are, of course, open questions. We have studied a particular population and a particular medical condition that is accompanied by stigma, depression and physical deterioration in ways that other chronic illnesses are not.

Nevertheless, we cannot resist speculating on the broader implications of our findings. Our results illustrate how the benefits of medical innovation are not limited to direct effects on health or survival, but can also work through changes in behavior. Our results also suggest that policies that provide better access to health care and enhance human capital can alleviate persistent and intractable social problems. Policies surrounding both domestic violence and illicit drug use often utilize criminal sanctions and attempt to change attitudes;

policies directed specifically at women also attempt to provide support for those who have been abused. Our findings suggest a complementary approach focused on interventions that increase women's human capital.

\section{References}

AIDSinfo, "Guidelines for the Use of Antiretroviral Agents in HIV-1-Infected Adults and 
Adolescents," http://aidsinfo.nih.gov/guidelines 2014.

Aizer, Anna, "The Gender Wage Gap and Domestic Violence," American Economic Review, 2010, 100 (4), 1847-1859.

Alvira-Hammond, Marta, Monica A Longmore, Wendy D Manning, and Peggy C Giordano, "Gainful Activity and Intimate Partner Aggression in Emerging Adulthood," Emerging Adulthood, 2014, 2 (2), 116-127.

Anderberg, Dan and Helmut Rainer, "Economic Abuse: A Theory of Intrahousehold Sabotage," Journal of Public Economics, 2013, 97, 282-295.

Angelucci, Manuela, "Love on the Rocks: Domestic Violence and Alcohol Abuse in Rural Mexico," The BE Journal of Economic Analysis 65 Policy, 2008, 8 (1), 1935-1682.

Anglin, M Douglas, Chih-Fen Kao, Lisa L Harlow, Katharine Peters, and Mary W Booth, "Similarity of Behavior within Addict Couples. Part I. Methodology and Narcotics Patterns," International Journal of the Addictions, 1987, 22 (6), 497-520.

Barkan, Susan E, Sandra L Melnick, Susan Preston-Martin, Kathleen Weber, Leslie A Kalish, Paolo Miotti, Mary Young, Ruth Greenblatt, Henry Sacks, and Joseph Feldman, "The Women's Interagency HIV Study," Epidemiology, 1998, 9 (2), 117-125.

Becker, Gary S, "Health as Human Capital: Synthesis and Extensions," Oxford Economic Papers, 2007, 59 (3), 379-410.

_ and Kevin M Murphy, "A Theory of Rational Addiction," Journal of Political Economy, 1988, $96(4), 675-700$.

Ben-Porath, Yoram, "The Production of Human Capital and The Life Cycle of Earnings," Journal of Political Economy, 1967, 75 (4), 352-365. 
Bertrand, Marianne, Esther Duflo, and Sendhil Mullainathan, "How Much Should We Trust Differences-in-Differences Estimates?," Quarterly Journal of Economics, 2004, $119(1), 249-275$.

Bhaskaran, K, O Hamouda, M Sannes, and et al., "Changes in the Risk of Death after HIV Seroconversion Compared with Mortality in the General Population," Journal of the American Medical Association, 2008, 300 (1), 51-59.

Black, Michele C, Kathleen C Basile, Matthew J Breiding, Sharon G Smith, Mikel L Walters, Melissa T Merrick, Jieru Chen, and Mark R Stevens, "The National Intimate Partner and Sexual Violence Survey: 2010 Summary Report," Technical Report, Centers for Disease Control and Prevention 2011.

Black, Sandra, Paul Devereux, and Kjell G Salvanes, "From the Cradle to the Labor Market? The Effect of Birth Weight on Adult Outcomes," Quarterly Journal of Economics, 2007, 122 (1), 409-439.

Bobonis, Gustavo J, Melissa González-Brenes, and Roberto Castro, "Public Transfers and Domestic Violence: The Roles of Private Information and Spousal Control," American Economic Journal: Economic Policy, 2013, 5 (1), 179-205.

Boles, Sharon M and Karen Miotto, "Substance Abuse and Violence: A Review of the Literature," Aggression and Violent Behavior, 2003, 8 (2), 155-174.

Bowlus, Audra J and Shannon Seitz, "Domestic Violence, Employment, and Divorce," International Economic Review, 2006, 47 (4), 1113-1149.

Browne, Angela, Amy Salomon, and Shari S Bassuk, "The Impact of Recent Partner Violence on Poor Women's Capacity to Maintain Work," Violence Against Women, 1999, 5 (4), 393-426. 
Carrell, Scott E and Mark L Hoekstra, "Externalities in the Classroom: How Children Exposed to Domestic Violence Affect Everyone's Kids," American Economic Journal: Applied Economics, 2010, 2 (1), 211-228.

Catalano, Shannan M, Intimate Partner Violence, 1993-2010, US Department of Justice, Office of Justice Programs, Bureau of Justice Statistics, 2012.

CDC, "HIV Surveillance Report," Technical Report 2015.

Cesur, Resul and Joseph J Sabia, "When War Comes Home: The Effect of Combat Service on Domestic Violence," Review of Economics and Statistics, 2016, 98 (2), 209-225.

Cohen, Mardge, Catherine Deamant, Susan Barkan, Jean Richardson, Mary Young, Susan Holman, Kathryn Anastos, Judith Cohen, and Sandra Melnick, "Domestic Violence and Childhood Sexual Abuse in HIV-Infected Women and Women at Risk for HIV," The American Journal of Public Health, 2000, 90 (4), 560-565.

Corman, Hope, Dhaval M Dave, Dhiman Das, and Nancy E Reichman, "Effects of Welfare Reform on Illicit Drug Use of Adult Women," Economic Inquiry, 2013, 51 (1), 653-674.

Denning, Paul and Elizabeth DiNenno, "Communities in Crisis: Is There A Generalized HIV Epidemic in Impoverished Urban Areas of the United States," in "XVIII international AIDS conference" 2010.

Detels, R, P Tarwater, JP Phair, J Margolick, SA Riddler, and A Muñoz, "Effectiveness of Potent Antiretroviral Therapies on the Incidence of Opportunistic Infections Before and after AIDS Diagnosis," AIDS, 2001, 15 (3), 347-355.

Devries, Karen M, Joelle Y Mak, Loraine J Bacchus, Jennifer C Child, Gail Falder, Max Petzold, Jill Astbury, and Charlotte H Watts, "Intimate Partner 
Violence and Incident Depressive Symptoms and Suicide Attempts: A Systematic Review of Longitudinal Studies," PLOS Medicine, 2013, 10 (5).

El-Bassel, Nabila, Louisa Gilbert, Elwin Wu, Hyun Go, and Jennifer Hill, "Relationship Between Drug Abuse and Intimate Partner Violence: a Longitudinal Study Among Women Receiving Methadone," American Journal of Public Health, 2005, 95 (3), $465-470$.

Erten, Bilge and Pinar Keskin, "For Better or for Worse?: Education and the Prevalence of Domestic Violence in Turkey," American Economic Journal: Applied Economics, 2018, $10(1), 64-105$.

Gelles, Richard J, "Abused Wives: Why Do They Stay?, Journal of Marriage and the Family, 1976, 38 (4), 659-668.

Goldman, Dana P and Yuhua Bao, "Effective HIV Treatment and The Employment of HIV+ Adults," Health Services Research, 2004, 39 (6p1), 1691-1712.

Greenfeld, Lawrence A, Michael R Rand, Diane Craven, Patsy A Klaus, Craig A Perkins, Cheryl Ringel, Greg Warchol, Cathy Maston, and James Alan Fox, "Violence by Intimates: Analysis of Data on Crimes by Current or Former Spouses, Boyfriends, and Girlfriends," Technical Report, US Department of Justice Washington, DC 1998.

Grossman, Michael, "On the Concept of Health Capital and the Demand for Health," Journal of Political Economy, 1972, 80 (2), 223-255.

Habyarimana, James, Bekezela Mbakile, and Cristian Pop-Eleches, "The Impact of HIV/AIDS and ARV Treatment on Worker Absenteeism Implications for African Firms," Journal of Human Resources, 2010, 45 (4), 809-839. 
Hart, Carl L, M Haney, RW Foltin, and MW Fischman, "Alternative Reinforcers Differentially Modify Cocaine Self-Administration by Humans," Behavioural Pharmacology, 2000, $11(1), 87-91$.

Heaton, Paul, "Sunday Liquor Laws and Crime," Journal of Public Economics, 2012, 96 (1), 42-52.

Heckman, James J and Paul A LaFontaine, "The American High School Graduation Rate: Trends and Levels," The Review of Economics and Statistics, 2010, 92 (2), 244-262.

Imbens, Guido W, "Matching Methods in Practice: Three Examples," Journal of Human Resources, 2015, 50 (2), 373-419.

Iyengar, Radha, "Does the Certainty of Arrest Reduce Domestic Violence? Evidence from Mandatory and Recommended Arrest Laws," Journal of Public Economics, 2009, 93 (1), $85-98$.

Jaffe, JH and AB Jaffe, "Neurobiology of Opiates and Opioids," in M. Galanter and H.D. Kleber, eds., Textbook of Substance Abuse Treatment, American Psychiatric Press Washington, DC 1999, pp. 11-19.

Jayachandran, Seema and Adriana Lleras-Muney, "Life Expectancy and Human Capital Investments: Evidence from Maternal Mortality Declines," Quarterly Journal of Economics, 2009, 124 (1), 349-397.

Johnson, Wendi L, Peggy C Giordano, Monica A Longmore, and Wendy D Manning, "Intimate Partner Violence and Depressive Symptoms During Adolescence and Young Adulthood," Journal of Health and Social Behavior, 2014, 55 (1), 39-55.

Johnson, Wendy A and Huibrie C Pieters, "Intimate Partner Violence among Women Diagnosed with Cancer," Cancer Nursing, 2016, 39 (2), 87-96. 
Karaca-Mandic, Pinar, Edward C Norton, and Bryan Dowd, "Interaction Terms in Nonlinear Models," Health Services Research, 2012, 47 (1pt1), 255-274.

Laub, John H and Robert J Sampson, "Understanding Desistance from Crime," Crime and Justice, 2001, 28, 1-69.

Mayer, Christopher, Edward Morrison, Tomasz Piskorski, and Arpit Gupta, "Mortgage Modification and Strategic Behavior: Evidence from a Legal Settlement with Countrywide," American Economic Review, 2014, 104 (9), 2830-57.

Mocroft, Amanda and Jens D Lundgren, "Starting Highly Active Antiretroviral Therapy: Why, When and Response to HAART," Journal of Antimicrobial Chemotherapy, 2004, 54 (1), 10-13.

Oster, Emily, Ira Shoulson, and E Dorsey, "Limited Life Expectancy, Human Capital and Health Investments," American Economic Review, 2013, 103 (5), 1977-2002.

Ostrow, DG, A. Monjan, J. Joseph, M. VanRaden, R. Fox, L. Kingsley, J. Dudley, and J. Phair, "HIV-Related Symptoms and Psychological Functioning in a Cohort of Homosexual Men," American Journal of Psychiatry, 1989, 146 (6), 737.

Papageorge, Nicholas W, "Why Medical Innovation is Valuable: Health, Human Capital, and the Labor Market," Quantitative Economics, 2016, 7 (3), 671-725.

Pellowski, Jennifer A, Seth C Kalichman, Karen A Matthews, and Nancy Adler, "A Pandemic of the Poor: Social Disadvantage and the US HIV Epidemic," American Psychologist, 2013, 68 (4), 197.

Phil, R. and J Peterson, "Alcohol/Drug Use and Aggressive Behavior," in S. Hodgins, ed., Mental Disorder and Crime, Crime and Mental Disorder Advanced Study Institute Sage 1993, pp. 263-283. 
Pollak, Robert A, "An Intergenerational Model of Domestic Violence," Journal of Population Economics, 2004, 17 (2), 311-329.

Pronyk, Paul M, James R Hargreaves, Julia C Kim, Linda A Morison, Godfrey Phetla, Charlotte Watts, Joanna Busza, and John DH Porter, "Effect of a Structural Intervention for the Prevention of Intimate-Partner Violence and HIV in Rural South Africa: A Cluster Randomised Trial," The Lancet, 2006, 368 (9551), 1973-1983.

Puhani, Patrick A, "The Treatment Effect, The Cross Difference, and the Interaction Term in Nonlinear "Difference-in-Differences" Models," Economics Letters, 2012, 115 (1), $85-87$.

Robins, Lee N, "Vietnam Veterans' Rapid Recovery from Heroin Addiction: A Fluke or Normal Expectation?," Addiction, 1993, 88 (8), 1041-1054.

Stevenson, Betsey and Justin Wolfers, "Bargaining in the Shadow of the Law: Divorce Laws and Family Distress," Quarterly Journal of Economics, 2006, 121 (1), 267-288.

Swanberg, Jennifer E and Caroline Macke, "Intimate Partner Violence and the Workplace Consequences and Disclosure," Journal of Women and Social Work, 2006, 21 (4), $391-406$.

Thirumurthy, Harsha, Joshua Graff Zivin, and Markus Goldstein, "The Economic Impact of AIDS Treatment Labor Supply in Western Kenya," Journal of Human Resources, 2008, $43(3), 511-552$.

Tjaden, Patricia and Nancy Thoennes, "Full Report of the Prevalence, Incidence, and Consequences of Violence Against Women," Technical Report, U.S. Department of Justice 2000.

Vanyukov, MM, MC Neale, HB Moss, and RE Tarter, "Mating Assortment and the Liability to Substance Abuse," Drug and Alcohol Dependence, 1996, 42 (1), 1-10. 
Volavka, Jan, Neurobiology of Violence, 2 ed., American Psychiatric Publishing, 2008.

Yeni, Patrick, "Update on HAART in HIV," Journal of Hepatology, 2006, 44, S100-S103.

Yi, Junjian, James J Heckman, Junsen Zhang, and Gabriella Conti, "Early Health Shocks, Intra-household Resource Allocation and Child Outcomes," The Economic Journal, 2015, 125 (588), F347-F371.

Zorza, Joan, "Woman Battering: A Major Cause of Homelessness," Clearinghouse Review, 1991, 25, 421. 


\section{Figures and Tables}

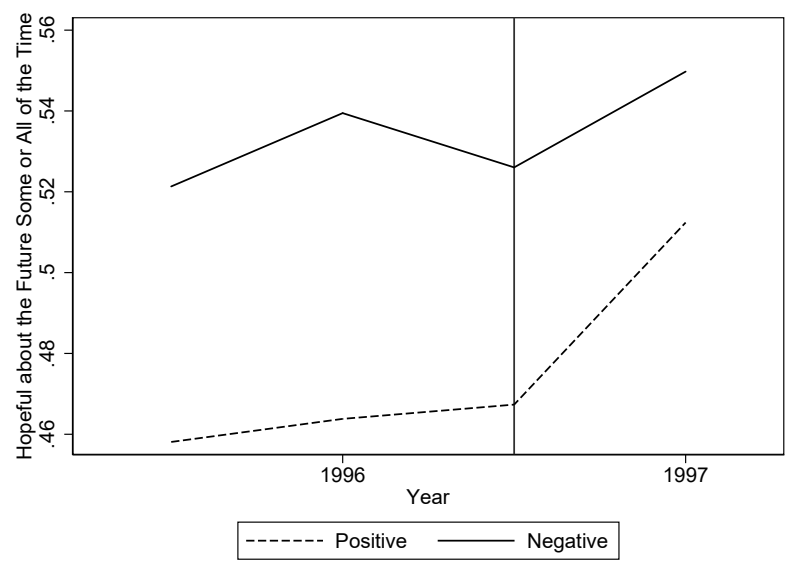

Figure 1: This figure shows the probability of reporting being hopeful about the future sometimes or all of the time the week before the visit for HIV + and HIV - women. 


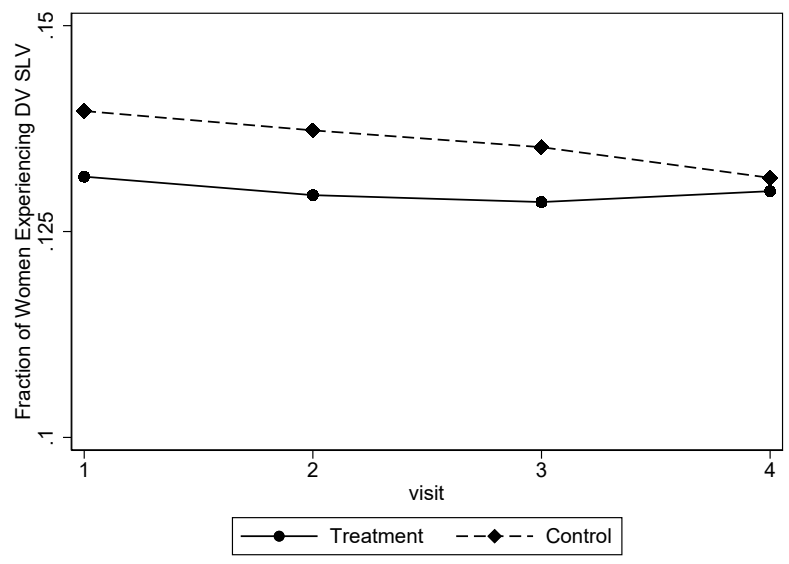

(a) Domestic Violence

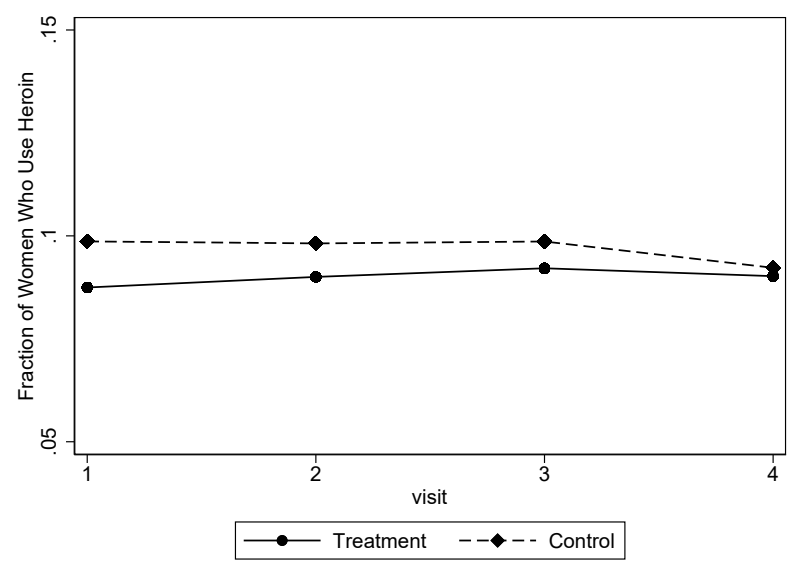

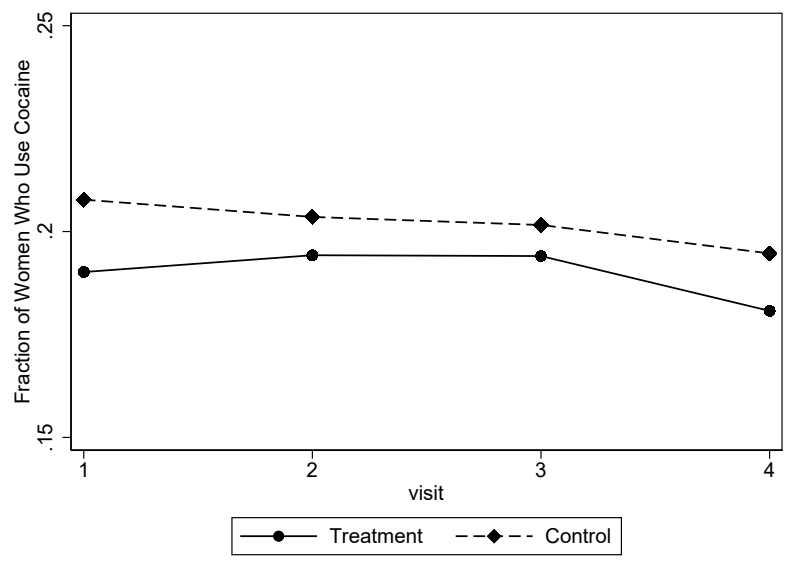

(b) Cocaine Use

(c) Heroin Use

Figure 2: This figure shows pre-HAART trends in outcomes. 


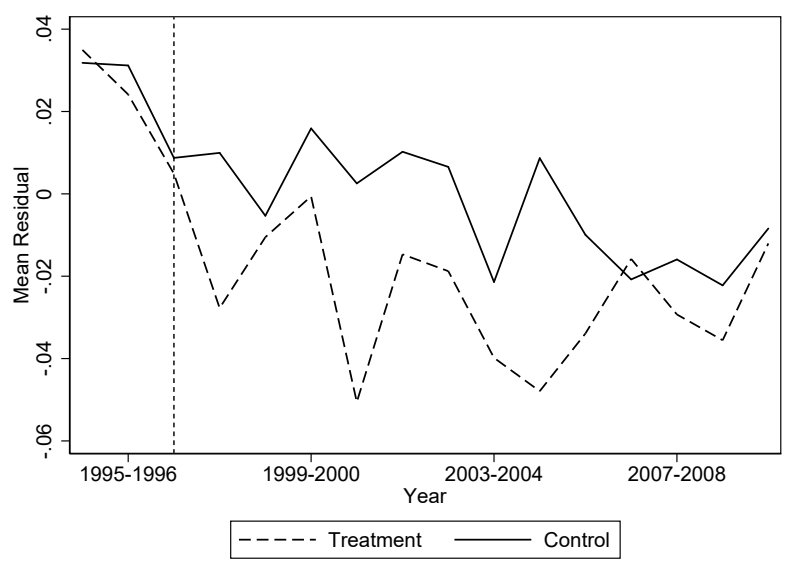

Figure 3: This figure shows residuals for the treatment group and the control group from a probit model of experiencing domestic violence, controlling for age, age squared, age cubed, race and site dummies. 
Table 1: Relationship Between Health, Drug Use, and Employment

\begin{tabular}{|c|c|}
\hline & $\begin{array}{c}\text { Full } \\
\text { Sample }\end{array}$ \\
\hline \multicolumn{2}{|c|}{ Domestic Violence } \\
\hline CD4 count & $\begin{array}{l}.00007 \\
(.0001)\end{array}$ \\
\hline Obs. & 13914 \\
\hline Mean & 0.054 \\
\hline Pseudo $R^{2}$ & 0.041 \\
\hline \multicolumn{2}{|c|}{ Cocaine Use } \\
\hline CD4 count & $\begin{array}{c}-.0004^{* * *} \\
(.0001)\end{array}$ \\
\hline Obs. & 31165 \\
\hline Mean & 0.109 \\
\hline Pseudo $R^{2}$ & 0.044 \\
\hline \multicolumn{2}{|c|}{ Heroin Use } \\
\hline CD4 count & $\begin{array}{l}-.0001 \\
(.0001)\end{array}$ \\
\hline Obs. & 31159 \\
\hline Mean & 0.044 \\
\hline Pseudo $R^{2}$ & 0.046 \\
\hline \multicolumn{2}{|c|}{ Employment } \\
\hline CD4 count & $\begin{array}{c}.0005^{* * *} \\
(.00007)\end{array}$ \\
\hline Obs. & 31305 \\
\hline Mean & 0.308 \\
\hline Pseudo $R^{2}$ & 0.057 \\
\hline
\end{tabular}

This table shows estimates from probit regressions relating health to domestic violence, illicit drug use and employment. Each specification is clustered at the individual level and includes controls for age at visit, age squared, age cubed, race dummies, and site dummies. 
Table 2: Violence, Drug Use and Employment by Time of AiDS Diagnosis

\begin{tabular}{lcc}
\hline \hline & Last visit pre AIDS & First visit with AIDS \\
\hline \hline Sexual abuse & 1.1 & 1.4 \\
Physical abuse & 4.7 & 4.2 \\
Coercion & 10.5 & 8.7 \\
Domestic violence & 11.9 & 9.5 \\
Cocaine use & 20.3 & 15.2 \\
Heroin use & 9.5 & 6.6 \\
Employed & 17.0 & 19.5 \\
\hline Observations & 800 & 2508 \\
\hline \hline
\end{tabular}

This table shows the percent of women who experienced each type of abuse in the six months prior to their last visit before an AIDS diagnosis and the six months prior to their first visit with AIDS. The sample is restricted to HIV+, low CD4 count women from the first cohort before HAART was introduced. AIDS is defined as having a CD4 count less than or equal to 200. 
Table 3: Summary Statistics

\begin{tabular}{|c|c|c|c|}
\hline & $\begin{array}{c}(1) \\
\text { Treatment } \\
\text { group }\end{array}$ & $\begin{array}{c}(2) \\
\text { Control } \\
\text { group }\end{array}$ & $\begin{array}{c}(3) \\
\text { Equal means } \\
\text { p-value }\end{array}$ \\
\hline Average age & 42 & 41 & .23 \\
\hline African American & 67 & 64 & .41 \\
\hline Hispanic & 20 & 22 & .68 \\
\hline White (Non-Hispanic) & 12 & 12 & .95 \\
\hline Other & 1 & 3 & .13 \\
\hline \multicolumn{4}{|l|}{ Education: } \\
\hline LT high school & 37 & 41 & .51 \\
\hline High school grad & 30 & 30 & .94 \\
\hline Some college & 23 & 22 & .82 \\
\hline College grad & 10 & 7 & .34 \\
\hline \multicolumn{4}{|l|}{ Pre-HAART Income: } \\
\hline$\leq 6000$ & 17 & 17 & .97 \\
\hline $6000-12000$ & 33 & 33 & .93 \\
\hline $12001-18000$ & 13 & 14 & .72 \\
\hline $18001-24000$ & 11 & 10 & .64 \\
\hline $24001-30000$ & 7 & 9 & .33 \\
\hline$>30000$ & 19 & 17 & .60 \\
\hline Employed re-HAART & 38 & 43 & .25 \\
\hline Married pre-HAART & 32 & 25 & .11 \\
\hline Lived with kids at baseline & 51 & 47 & .38 \\
\hline \multicolumn{4}{|l|}{ Risky Behaviors Pre-HAART (Ever): } \\
\hline Used crack & 22 & 23 & .79 \\
\hline Used powdered cocaine & 17 & 21 & .34 \\
\hline Used cocaine & 28 & 31 & .52 \\
\hline Used stimulants & 30 & 32 & .59 \\
\hline Used heroin & 18 & 16 & .50 \\
\hline \multicolumn{4}{|l|}{ Symptoms Pre-HAART (Ever): } \\
\hline Memory problems & 31 & 36 & .22 \\
\hline Numbness & 39 & 42 & .61 \\
\hline Weight loss & 33 & 27 & .23 \\
\hline Mental confusion & 17 & 20 & .50 \\
\hline Night sweats & 35 & 41 & .22 \\
\hline \multicolumn{4}{|c|}{ Pre-HAART Domestic Violence (Ever): } \\
\hline Experienced sex abuse & 5 & 10 & .09 \\
\hline Experienced physical abuse & 17 & 19 & .65 \\
\hline Experienced coercion & 26 & 28 & .59 \\
\hline Experienced domestic violence & 27 & 34 & .14 \\
\hline Observations & 166 & 269 & \\
\hline Person-Visits & 2477 & 4192 & \\
\hline
\end{tabular}

The full sample includes all women from the first cohort who answered questions about domestic violence, employment, and illicit drug use, as well as all controls used. The treatment group is defined as having a minimum pre-HAART CD4 count between 300 and 399. High CD4 refers to minimum pre-HAART CD4 count greater than or equal to 400. Income is measured as yearly household income. Cocaine is defined as crack or powdered cocaine use. Stimulants are defined as crack, cocaine, (illicit) methadone, or methamphetamine. Domestic violence is defined as physical or sexual abuse or coercion by an intimate partner or spouse. Coercion indicates that the partner threatened to hurt or kill the subject or prevented her from: leaving or entering her home, seeing friends, making telephone calls, getting or keeping a job, continuing her education, or seeking medical attention. Column (3) shows p-values from the tests of differences in means between the treatment group and the control group. 
Table 4: Test of Equality of Pre-HAART Trends

\begin{tabular}{lc}
\hline \hline Outcome & $\mathrm{p}$-value \\
\hline Domestic violence & 0.258 \\
Cocaine use & 0.091 \\
Heroin use & 0.307 \\
\hline Joint significance & 0.148 \\
\hline \hline
\end{tabular}

This table shows the p-values from tests that the pre-HAART trends in outcomes are parallel. For each outcome, we regress the outcome on age, age squared, race indicators, site of visit indicators, six-month time dummies, an indicator for being in the treatment group, and an interaction of the time bins and the treatment group. We then test that the pre-HAART interactions are zero.

Table 5: Health, Violence and Drug Use: Probit Coefficients

\begin{tabular}{lcccccc}
\hline \hline & \multicolumn{2}{c}{ Domestic Violence } & \multicolumn{2}{c}{ Cocaine Use } & \multicolumn{2}{c}{ Heroin Use } \\
& {$[1]$} & {$[2]$} & {$[3]$} & {$[4]$} & {$[5]$} & {$[6]$} \\
\hline Full Sample & & & & & & \\
HAART available & $-.365^{* * *}$ & $-.235^{* * *}$ & $-.203^{* * *}$ & $-.304^{* * *}$ & $-.163^{* * *}$ & $-.273^{* * *}$ \\
& $(.075)$ & $(.085)$ & $(.052)$ & $(.058)$ & $(.058)$ & $(.068)$ \\
Treatment group & -.061 & -.023 & .043 & .071 & .091 & .122 \\
& $(.116)$ & $(.116)$ & $(.098)$ & $(.099)$ & $(.113)$ & $(.114)$ \\
Treatment $\times$ HAART & $-.202^{*}$ & $-.213^{*}$ & $-.171^{* *}$ & -.129 & $-.276^{* * *}$ & $-.242^{* *}$ \\
& $(.117)$ & $(.121)$ & $(.080)$ & $(.084)$ & $(.098)$ & $(.104)$ \\
Obs. & 6669 & 6669 & 16265 & 16265 & 16261 & 16261 \\
\hline Black Sample & & & & & & \\
HAART available & $-.411^{* * *}$ & $-.321^{* * *}$ & $-.246^{* * *}$ & $-.355^{* * *}$ & $-.177^{* *}$ & $-.365^{* * *}$ \\
& $(.092)$ & $(.098)$ & $(.068)$ & $(.072)$ & $(.081)$ & $(.082)$ \\
Treatment group & -.004 & .039 & .085 & .130 & .086 & .096 \\
& $(.140)$ & $(.141)$ & $(.126)$ & $(.128)$ & $(.147)$ & $(.152)$ \\
Treatment $\times$ HAART & $-.273^{*}$ & $-.289^{*}$ & -.165 & -.152 & $-.267^{*}$ & -.216 \\
& $(.145)$ & $(.148)$ & $(.105)$ & $(.108)$ & $(.139)$ & $(.143)$ \\
Obs. & 4280 & 4280 & 9355 & 9355 & 9352 & 9352 \\
\hline Basic controls & $\mathrm{N}$ & $\mathrm{Y}$ & $\mathrm{N}$ & $\mathrm{Y}$ & $\mathrm{N}$ & $\mathrm{Y}$ \\
\hline \hline
\end{tabular}

This table shows difference-in-differences probit model estimates where the outcome variable is having experienced domestic violence, used cocaine, or used heroin since the last visit. Basic controls include age at visit, age squared, age cubed, race (Caucasian omitted), and site of visit (Chicago omitted). In all specifications, errors are clustered at the individual level. 
Table 6: Health, Violence and Drug Use: Marginal Effects

\begin{tabular}{lcccccc}
\hline \hline & \multicolumn{2}{c}{ Domestic Violence } & \multicolumn{2}{c}{ Cocaine Use } & \multicolumn{2}{c}{ Heroin Use } \\
& {$[1]$} & {$[2]$} & {$[3]$} & {$[4]$} & {$[5]$} & {$[6]$} \\
\hline Full Sample & & & & & & \\
Treatment $\times$ HAART & $-0.015^{*}$ & $-0.017^{*}$ & $-0.029^{* *}$ & -0.022 & $-0.022^{* * *}$ & $-0.019^{* *}$ \\
& $(0.008)$ & $(0.009)$ & $(0.013)$ & $(0.014)$ & $(0.007)$ & $(0.008)$ \\
& 0.068 & 0.063 & 0.027 & 0.109 & 0.003 & 0.011 \\
Observations & 6669 & 6669 & 16265 & 16265 & 16261 & 16261 \\
\hline Pre-HAART treatment group mean & 0.103 & 0.103 & 0.178 & 0.178 & 0.087 & 0.087 \\
Mean & 0.063 & 0.063 & 0.121 & 0.121 & 0.052 & 0.052 \\
Pseudo $R^{2}$ & 0.026 & 0.059 & 0.006 & 0.065 & 0.009 & 0.090 \\
\hline \hline Black Sample & & & & & & \\
Treatment $\times$ HAART & $-0.021^{* *}$ & $-0.024^{* *}$ & -0.034 & -0.028 & $-0.022^{* *}$ & -0.016 \\
& $(0.011)$ & $(0.011)$ & $(0.021)$ & $(0.022)$ & $(0.010)$ & $(0.011)$ \\
Observations & 0.044 & 0.034 & 0.103 & 0.201 & 0.037 & 0.151 \\
\hline Pre-HAART treatment group mean & 4280 & 4280 & 9355 & 9355 & 9352 & 9352 \\
Mean & 0.130 & 0.130 & 0.228 & 0.228 & 0.089 & 0.089 \\
Pseudo $R^{2}$ & 0.069 & 0.069 & 0.145 & 0.145 & 0.053 & 0.053 \\
\hline Basic controls & 0.033 & 0.057 & 0.007 & 0.058 & 0.009 & 0.103 \\
\hline \hline
\end{tabular}

This table shows the marginal effects of the interaction term from the difference in differences probit models. Standard errors are presented in parenthesis, and p-values are found below. Basic controls include age at visit, age squared, age cubed, race (Caucasian omitted), and site of visit (Chicago omitted). In all specifications, errors are clustered at the individual level. 
Table 7: CD4 CounT

\begin{tabular}{lcc}
\hline \hline & {$[1]$} & {$[2]$} \\
\hline \hline Full Sample & & \\
HAART available & $(12.824)$ & $(13.338)$ \\
& $-252.501^{* * * *}$ & $-245.119^{* * *}$ \\
Treatment group & $(14.061)$ & $(14.442)$ \\
& $137.740^{* * *}$ & $136.016^{* * *}$ \\
Treatment $\times$ HAART & $(21.814)$ & $(21.613)$ \\
& 6524 & 6524 \\
Obs. & 424.2 & 424.2 \\
Pre-HAART treatment group mean & 560.1 & 560.1 \\
Mean & 0.069 & 0.090 \\
$R^{2}$ & & \\
\hline \hline Black Sample & $-90.840^{* * *}$ & $-85.041^{* * *}$ \\
HAART available & $(17.268)$ & $(17.701)$ \\
& $-267.766^{* * *}$ & $-265.419^{* * *}$ \\
Treatment group & $(17.346)$ & $(18.838)$ \\
& $142.861^{* * *}$ & $139.667^{* * *}$ \\
Treatment $\times$ HAART & $(25.966)$ & $(25.727)$ \\
& 4189 & 4189 \\
Obs. & 421.9 & 421.9 \\
\hline Pre-HAART treatment group mean & 559.9 & 559.9 \\
Mean & 0.080 & 0.083 \\
\hline \hline Basic controls & $\mathrm{N}$ & $\mathrm{Y}$ \\
\hline \hline
\end{tabular}

This table shows estimates from OLS difference-in-differences models where the outcome variable is CD4 count. Basic controls include age at visit, age squared, age cubed, race (Caucasian omitted), and site of visit (Chicago omitted). In all specifications, errors are clustered at the individual level. 
Table 8: Depression Score And Symptoms

\begin{tabular}{lcccc}
\hline \hline & \multicolumn{3}{c}{ CESD Score } & \multicolumn{2}{c}{ Any Symptoms } \\
& {$[1]$} & {$[2]$} & {$[3]$} & {$[4]$} \\
\hline \hline Full Sample & & & & \\
HAART available & $-2.734^{* * *}$ & $-3.328^{* * *}$ & -.017 & $-.080^{* * *}$ \\
& $(.441)$ & $(.507)$ & $(.016)$ & $(.018)$ \\
Treatment group & $-2.406^{* * *}$ & $-2.507^{* * *}$ & -.016 & -.022 \\
& $(.871)$ & $(.872)$ & $(.030)$ & $(.029)$ \\
Treatment $\times$ HAART & .501 & .803 & .011 & .028 \\
& $(.720)$ & $(.718)$ & $(.027)$ & $(.026)$ \\
Obs. & 14324 & 14324 & 16765 & 16765 \\
\hline Pre-HAART treatment group mean & 16.55 & 16.55 & 0.45 & 0.45 \\
Mean & 15.95 & 15.95 & 0.44 & 0.44 \\
$R^{2}$ & 0.010 & 0.043 & 0.000 & 0.037 \\
\hline \hline Black Sample & & & & \\
HAART available & $-3.478^{* * *}$ & $-4.223^{* * *}$ & -.004 & $-.068^{* * *}$ \\
& $(.611)$ & $(.666)$ & $(.021)$ & $(.023)$ \\
Treatment group & $-3.398^{* * *}$ & $-3.074^{* * *}$ & .023 & .026 \\
& $(1.067)$ & $(1.056)$ & $(.040)$ & $(.038)$ \\
Treatment $\times$ HAART & 1.486 & $1.702^{*}$ & -.045 & -.026 \\
Obs. & $(.940)$ & $(.936)$ & $(.035)$ & $(.034)$ \\
\hline Pre-HAART treatment group mean & 8205 & 8205 & 9608 & 9608 \\
Mean & 15.97 & 15.97 & 0.48 & 0.48 \\
$R^{2}$ & 15.69 & 15.69 & 0.44 & 0.44 \\
\hline \hline Basic controls & 0.014 & 0.053 & 0.001 & 0.050 \\
\hline \hline
\end{tabular}

This table shows estimates from OLS difference-in-differences models. The first outcome variable is CES-D Scale Score, where higher values mean depression is more likely. The second outcome is having any symptom (fever, memory problem, numbness, weight loss, mental confusion, or night sweats). Results for having any symptom are robust to a probit specification, and available upon request. Basic controls include age at visit, age squared, age cubed, race (Caucasian omitted), and site of visit (Chicago omitted). In all specifications, errors are clustered at the individual level. 
Table 9: Drug Use And Violence

\begin{tabular}{lccc}
\hline \hline & {$[1]$} & {$[2]$} & {$[3]$} \\
\hline \hline Heroin use & $-.143^{* * *}$ & $-.141^{* * *}$ & $-.143^{* * *}$ \\
Cocaine use & $.144^{* * *}$ & $.142^{* * *}$ & $.119^{* * *}$ \\
Age & -.010 & -.010 & -.009 \\
Age squared & .00004 & .00005 & .00004 \\
Age cubed & $1.62 \mathrm{e}-07$ & $1.54 \mathrm{e}-07$ & $1.86 \mathrm{e}-07$ \\
Yearly income 6001-12000 &. & -.007 & -.007 \\
Yearly income 12001-18000 &. & -.009 & -.009 \\
Yearly income 18001-24000 &. & -.005 & -.004 \\
Yearly income 24001-30000 &. & -.015 & -.015 \\
Yearly income > 30000 &. & .0001 & .0005 \\
Employed &. & .002 & .002 \\
Yearly income 6001-12000, employed &. & -.002 & -.002 \\
Yearly income 12001-18000, employed &. & -.002 & -.002 \\
Yearly income 18001-24000, employed &. & -.019 & -.020 \\
Yearly income 24001-30000, employed &. & .004 & .004 \\
Yearly income > 30000, employed &. & -.006 & -.006 \\
Married &. & $.014^{*}$ & $.014^{*}$ \\
Not married, lives with prtnr &. & $.020^{* * *}$ & $.020^{* * *}$ \\
Widowed &. & -.012 & -.012 \\
Divorced/annuled &. & .005 & .005 \\
Separated &. & .009 & .008 \\
Other marital status &. & .003 & .003 \\
Used marijuana SLV &. &. & $.018^{* * *}$ \\
Never smoker &. &. & .031 \\
Current smoker &. &. & .011 \\
Light (lt 3 drinks/wk) &. &. & -.003 \\
Moderate (3-13 drinks/wk) &. &. & .005 \\
Heavier (gt 13 drinks/wk) &. &. & $.026^{* *}$ \\
No. male sex prtnr SLV & .0056 & 0.056 & 0.056 \\
Obs. & & & \\
Mean & .0005 \\
\hline \hline
\end{tabular}

This table shows estimates from regressions of violence on illicit drug use. The sample is restricted to women from the first cohort who answered questions about domestic violence, which is defined in Table 3. Each specification uses individual level fixed effects. SLV means "since last visit." 
Table 10: Employment, Marginal Effects

\begin{tabular}{lcc}
\hline \hline & {$[1]$} & {$[2]$} \\
\hline Full Sample & & \\
Treatment $\times$ HAART & $0.055^{*}$ & $0.048^{*}$ \\
& $(0.030)$ & $(0.029)$ \\
Observations & 0.065 & 0.099 \\
Pre-HAART treatment group mean & 16348 & 16348 \\
Mean & 0.253 & 0.253 \\
Pseudo $R^{2}$ & 0.335 & 0.335 \\
\hline Black Sample SaART $_{\text {Treatment } \times \text { HAAR }}$ & 0.002 & 0.060 \\
\hline & & \\
Observations & $0.081^{*}$ & $0.077^{*}$ \\
Pre-HAART treatment group mean & 0.223 & 0.223 \\
Mean & $0.041)$ & $(0.040)$ \\
Pseudo $R^{2}$ & 0.003 & 0.054 \\
\hline \hline Basic controls & $\mathrm{N}$ & $\mathrm{Y}$ \\
\hline \hline
\end{tabular}

This table shows the marginal effects of the interaction term from the difference in differences probit models. The outcome of interest is being employed at the time of visit. Standard errors are presented in parenthesis, and p-values are found below. Basic controls include age at visit, age squared, age cubed, race (Caucasian omitted), and site of visit (Chicago omitted). In all specifications, errors are clustered at the individual level. 
Table 11: Domestic Violence and Resources

\begin{tabular}{lccccc}
\hline \hline & {$[1]$} & {$[2]$} & {$[3]$} & {$[4]$} & {$[5]$} \\
\hline \hline Employed & $-.011^{* *}$ &. & $-.011^{* *}$ & $-.010^{* *}$ & $-.008^{*}$ \\
Yearly income 6001-12000 &. & -.009 & -.008 & -.008 & -.007 \\
Yearly income 12001-18000 &. & $-.016^{* *}$ & $-.015^{* *}$ & $-.015^{* *}$ & $-.015^{* *}$ \\
Yearly income 18001-24000 &. & -.011 & -.010 & -.011 & -.011 \\
Yearly income 24001-30000 &. & $-.020^{* *}$ & $-.018^{* *}$ & $-.019^{* *}$ & $-.020^{* *}$ \\
Yearly income $>30000$ &. & -.003 & -.0006 & -.002 & -.004 \\
Age & $-.025^{* *}$ & $-.025^{* * *}$ & $-.024^{* *}$ & $-.025^{* * *}$ & $-.025^{* * *}$ \\
Age squared & .0003 & .0003 & .0003 & .0003 & .0003 \\
Age cubed & $-9.10 \mathrm{e}-07$ & $-8.32 \mathrm{e}-07$ & $-8.53 \mathrm{e}-07$ & $-9.14 \mathrm{e}-07$ & $-9.60 \mathrm{e}-07$ \\
Obs. & 25526 & 25526 & 25526 & 25526 & 25526 \\
Mean & 0.067 & 0.067 & 0.067 & 0.067 & 0.067 \\
$R^{2}$ & 0.022 & 0.022 & 0.023 & 0.023 & 0.032 \\
\hline Basic controls & $\mathrm{Y}$ & $\mathrm{Y}$ & $\mathrm{Y}$ & $\mathrm{Y}$ & $\mathrm{Y}$ \\
Demographic controls & $\mathrm{N}$ & $\mathrm{N}$ & $\mathrm{N}$ & $\mathrm{Y}$ & $\mathrm{Y}$ \\
Risky behaviors & $\mathrm{N}$ & $\mathrm{N}$ & $\mathrm{N}$ & $\mathrm{N}$ & $\mathrm{Y}$ \\
\hline \hline
\end{tabular}

This table shows results from an OLS model with individual level fixed effects where the outcome variable is experiencing domestic violence since the last visit, which is defined in Table 3 . Basic controls include age, age squared, and age cubed. Demographic controls include indicator variables for marital status (never married omitted). Risky behaviors include indicator variables for drug use, cigarette smoking, alcohol use, and the number of male sex partners. 


\section{Appendix A Additional Tables and Figures}

This appendix contains additional tables and figures from "Health, Human Capital and Domestic Violence." We discuss them in the order that they appear in the main text of the paper.

Table A1 shows that demographics, being in the treatment group, and experiencing violence pre-HAART are not related to the likelihood of leaving the sample or the number of visits that one stays in the sample. We also test if observations are missing at random. We regress missing visits on an indicator for the treatment group, lagged CD4 count, and an interaction between lagged CD4 and the treatment group along with the basic controls discussed in Section 4. Table A2 shows the coefficients on the interaction. Although health is a significant predictor of missing a visit, we find that health does not have differential effects on the likelihood of missing a visit in the treatment group versus the control group.

To verify that the differences-in-differences approach is valid, we conduct an event study. We regress each of the main outcomes we study (domestic violence, cocaine use and heroin use) on dummies for the periods leading up to the introduction of HAART and the periods after HAART introduction, an indicator for the treatment group, and interactions between the treatment group and the lead/lag periods. We also include the basic controls discussed in Section 4. In Figure A1 we show results from the interactions between the treatment group and the time periods, plotting coefficients. Importantly, we find that the periods leading up to HAART are never significantly negative, implying that our findings are not driven by trends that existed before the introduction of HAART.

To test that black women were affected more by the introduction of HAART, we interact an indicator for the treatment group with HAART availability and being black. Table A3 shows the findings from this triple interaction and is described in Section 4.1 .

To test that our results are not driven by survival bias, we estimate models including only women who stayed in the survey for at least 15 visits (about 7.5 years). These results 
are shown in Table A4. As an additional robustness check, we also conduct our analysis using propensity score weighting. Table A5 shows the normalized differences for observable characteristics of the sample. Given that these differences are all very small, we conclude that the treatment group and high CD4 count HIV+ women are quite similar prior to HAART. In fact, no outcomes are above the threshold of .25 suggested by Imbens (2015). Table A6 shows the results from our propensity score estimation. We estimate both a linear specification and a quadratic specification. Again, we follow the algorithm proposed by Imbens (2015) in choosing the controls for the propensity score matching. Table A6 shows that prior to HAART, the groups were very similar in terms of violence, cocaine use and heroin use. However, we find that the introduction of HAART had a significant impact on the treatment group in comparison to the control group. Propensity score matching requires that the two groups have good overlap of the score, and we show that this is the case in Figure A2. This figure shows the overlap in propensity scores between the treatment group and the control group for domestic violence. The figures for other outcomes are quite similar and are available upon request from the corresponding author.

Turning to mechanisms, we allow for the fact that drug use and domestic violence may be correlated and jointly estimate the impact of HAART on violence and cocaine use in Tables A7 and heroin use in Tables A8, Finally, Tables A9 and A10 show regressions examining the relationships amongst employment, health, and cocaine use and heroin use, respectively. 


\section{Appendix A.1 Supplemental Tables and Figures}

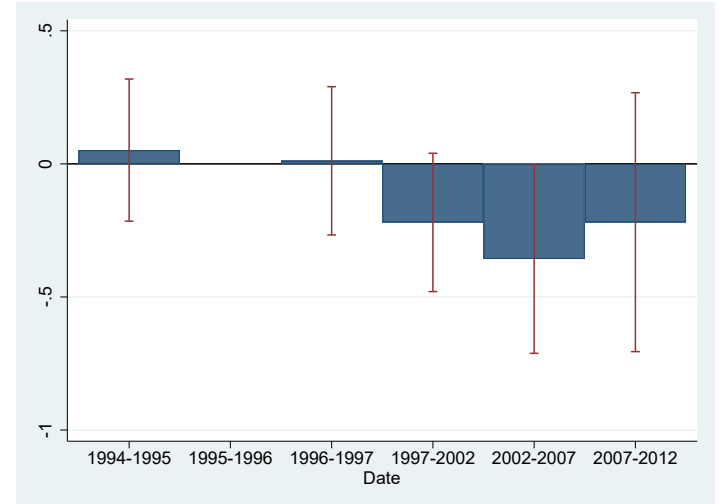

(a) Domestic Violence, HIV+ High CD4

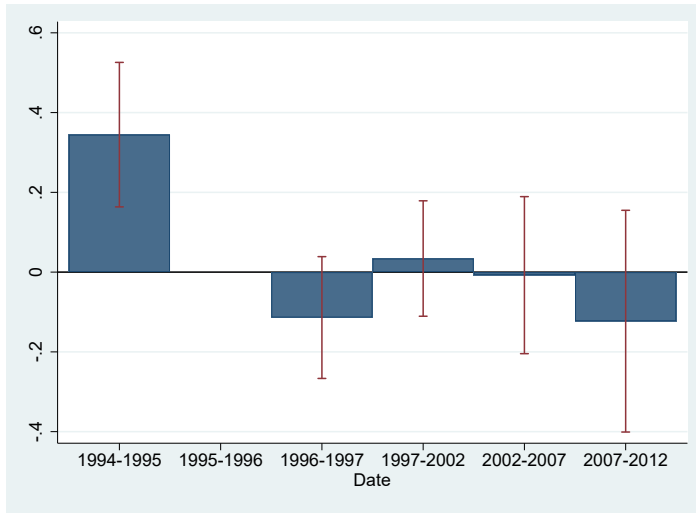

(b) Cocaine Use, HIV+ High CD4

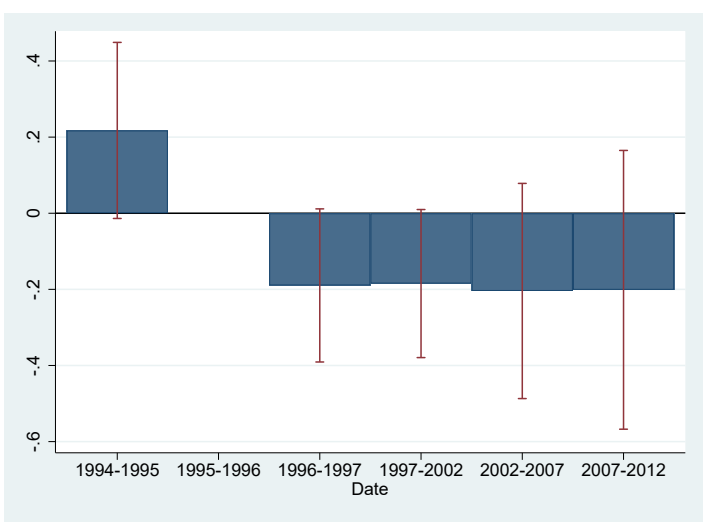

(c) Heroin Use, HIV+ High CD4

Figure A1: This figure shows coefficients of the interaction between the treatment group and the periods leading up to and lagging HAART. Each bar represents the estimated coefficient and the capped, vertical line show the estimated $90 \%$ confidence interval. 


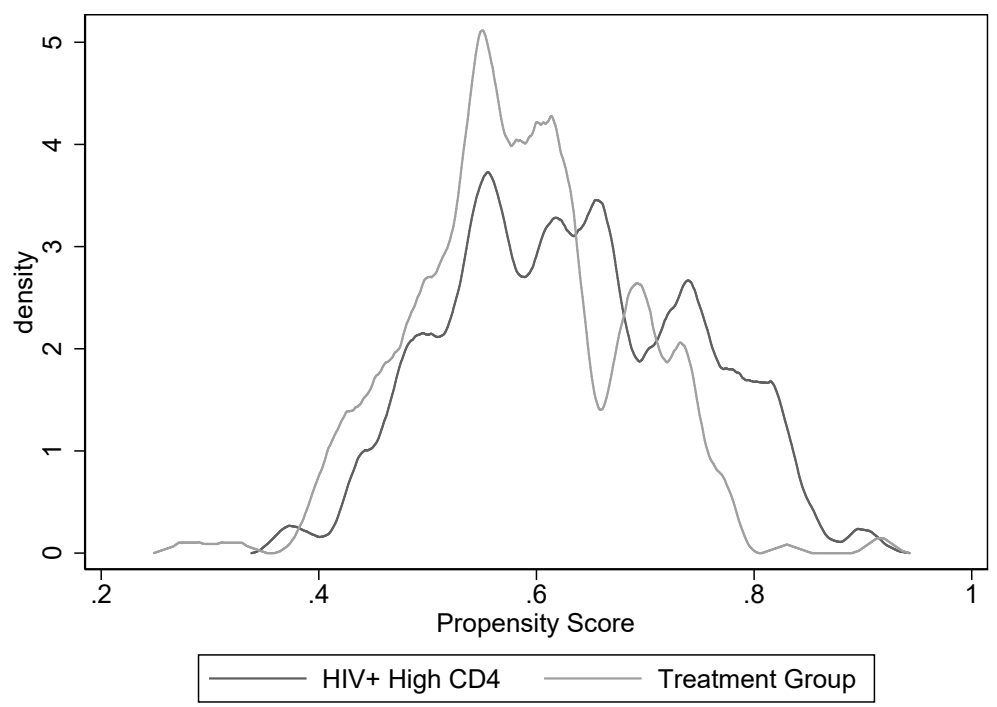

Figure A2: This figure shows overlap of the estimated propensity score using a linear specification for the treatment group and the control group. 
Table A1: Test of Non-Random Attrition

\begin{tabular}{|c|c|c|c|c|c|c|}
\hline \multirow[b]{2}{*}{ Treatment group } & \multicolumn{3}{|c|}{ Leaving the Sample } & \multicolumn{3}{|c|}{ No. of Visits in Study } \\
\hline & $\begin{array}{l}.147 \\
(.215)\end{array}$ & $\begin{array}{c}.093 \\
(.229)\end{array}$ & $\begin{array}{c}.098 \\
(.229)\end{array}$ & $\begin{array}{l}-.695 \\
(.817)\end{array}$ & $\begin{array}{l}.656 \\
(.799)\end{array}$ & $\begin{array}{l}-.645 \\
(.802)\end{array}$ \\
\hline Age & . & $\begin{array}{c}.054 \\
(.509)\end{array}$ & $\begin{array}{l}.049 \\
(.508)\end{array}$ & . & $\begin{array}{c}.681 \\
(1.592)\end{array}$ & $\begin{array}{c}.678 \\
(1.594)\end{array}$ \\
\hline Age squared & . & $\begin{array}{l}.001 \\
(.013)\end{array}$ & $\begin{array}{l}.001 \\
(.013)\end{array}$ & . & $\begin{array}{l}-.023 \\
(.042)\end{array}$ & $\begin{array}{l}-.023 \\
(.042)\end{array}$ \\
\hline Age cubed & . & $\begin{array}{c}-.00002 \\
(.0001)\end{array}$ & $\begin{array}{c}-.00002 \\
(.0001)\end{array}$ & . & $\begin{array}{l}.0002 \\
(.0004)\end{array}$ & $\begin{array}{l}.0002 \\
(.0004)\end{array}$ \\
\hline Black & . & $\begin{array}{l}.117 \\
(.356)\end{array}$ & $\begin{array}{l}.100 \\
(.358)\end{array}$ & . & $\begin{array}{l}-1.143 \\
(1.228)\end{array}$ & $\begin{array}{l}-1.177 \\
(1.239)\end{array}$ \\
\hline Hispanic & . & $\begin{array}{l}-.633 \\
(.438)\end{array}$ & $\begin{array}{l}-.641 \\
(.438)\end{array}$ & . & $\begin{array}{l}1.673 \\
(1.474)\end{array}$ & $\begin{array}{l}1.660 \\
(1.477)\end{array}$ \\
\hline Other race & . & $\begin{array}{l}-.128 \\
(.917)\end{array}$ & $\begin{array}{l}-.157 \\
(.924)\end{array}$ & . & $\begin{array}{l}-1.990 \\
(3.037)\end{array}$ & $\begin{array}{l}-2.022 \\
(3.044)\end{array}$ \\
\hline Violence pre-HAART & . & . & $\begin{array}{l}.101 \\
(.242)\end{array}$ & . & . & $\begin{array}{l}.187 \\
(.842)\end{array}$ \\
\hline Obs. & 435 & 435 & 435 & 435 & 435 & 435 \\
\hline Mean & 0.294 & 0.294 & 0.294 & 28.526 & 28.526 & 28.526 \\
\hline Pseudo $R^{2}$ & 0.001 & 0.065 & 0.066 & . & . & . \\
\hline$R^{2}$ & . & . & . & 0.002 & 0.102 & 0.102 \\
\hline
\end{tabular}

Columns 1-3 show estimated coefficients from a logit model where the outcome is leaving the study at any time. Columns 4-6 show results from an OLS model where the outcome is the number of visits that the woman stays in the study. In every specification, site of visit is controlled for (Chicago omitted).

Table A2: Missing Outcomes

\begin{tabular}{lccccc}
\hline \hline & $\begin{array}{c}\text { Domestic } \\
\text { Violence }\end{array}$ & $\begin{array}{c}\text { Cocaine } \\
\text { Use }\end{array}$ & $\begin{array}{c}\text { Heroin } \\
\text { Use }\end{array}$ & $\begin{array}{c}\text { Employ- } \\
\text { ment }\end{array}$ & Income \\
\hline \hline Treatment group & -.018 & -.001 & -.002 & -.008 & .018 \\
& $(.069)$ & $(.057)$ & $(.057)$ & $(.056)$ & $(.026)$ \\
Log CD4 & $-.017^{* * *}$ & $-.020^{* * *}$ & $-.019^{* * *}$ & $-.019^{* * *}$ & -.001 \\
& $(.003)$ & $(.003)$ & $(.003)$ & $(.003)$ & $(.001)$ \\
Treatment $\times$ CD4 & .005 & .001 & .002 & .002 & -.003 \\
& $(.012)$ & $(.010)$ & $(.010)$ & $(.009)$ & $(.004)$ \\
Obs. & 14949 & 23215 & 23215 & 23215 & 23215 \\
Mean & 0.078 & 0.080 & 0.081 & 0.077 & 0.023 \\
$R^{2}$ & 0.016 & 0.016 & 0.016 & 0.015 & 0.009 \\
\hline Basic controls & $\mathrm{Y}$ & $\mathrm{Y}$ & $\mathrm{Y}$ & $\mathrm{Y}$ & $\mathrm{Y}$ \\
\hline \hline
\end{tabular}

This table shows results from an OLS model where the outcome variable is an indicator for missing an observation for the event listed. Basic controls include age at visit, age squared, age cubed, race (Caucasian omitted), and site of visit (Chicago omitted). In all specifications, errors are clustered at the individual level. Visits from sites in Los Angeles and San Francisco are dropped from the domestic violence outcome. 
Table A3: Heterogeneity in Effects of HAART on Domestic Violence

\begin{tabular}{lcc}
\hline \hline & {$[1]$} & {$[2]$} \\
\hline \hline Panel A: Treatment vs Control Group Women \\
HAART available & $-.269^{* *}$ & -.123 \\
& $(.128)$ & $(.141)$ \\
Treatment Group & -.230 & -.205 \\
& $(.202)$ & $(.204)$ \\
Black & .242 & $.462^{* *}$ \\
& $(.153)$ & $(.180)$ \\
Treatment $\times$ HAART & -.005 & .002 \\
& $(.186)$ & $(.197)$ \\
AA $\times$ HAART & -.142 & -.162 \\
& $(.157)$ & $(.164)$ \\
Treatment $\times$ AA & .226 & .249 \\
& $(.246)$ & $(.247)$ \\
Treatment $\times$ AA $\times$ HAART & -.267 & -.296 \\
& $(.235)$ & $(.245)$ \\
Obs. & 6669 & 6669 \\
Mean & 0.063 & 0.063 \\
Pseudo $R^{2}$ & 0.030 & 0.061 \\
\hline Basic controls & $\mathrm{N}$ & $\mathrm{Y}$ \\
\hline \hline
\end{tabular}

This table shows difference-in-differences probit model estimates, where the outcome variable is experiencing domestic violence since the last visit. We also include dummy variables and interactions for women who are black to estimate heterogeneity in effects of HAART by race. Basic controls include age at visit, age squared, age cubed and site of visit (Chicago omitted). In all specifications, errors are clustered at the individual level. 
Table A4: Health, Violence and Drug Use: Marginal Effects of Women Who Did Not Die Within 7.5 Years of Study

\begin{tabular}{lcccccc}
\hline \hline & \multicolumn{2}{c}{ Domestic Violence } & \multicolumn{2}{c}{ Cocaine Use } & \multicolumn{2}{c}{ Heroin Use } \\
& {$[1]$} & {$[2]$} & {$[3]$} & {$[4]$} & {$[5]$} & {$[6]$} \\
\hline Full Sample & & & & & & \\
Treatment $\times$ HAART & $-0.016^{*}$ & $-0.017^{*}$ & $-0.034^{* *}$ & $-0.031^{* *}$ & $-0.022^{* * *}$ & $-0.021^{* * *}$ \\
& $(0.008)$ & $(0.009)$ & $(0.013)$ & $(0.013)$ & $(0.007)$ & $(0.007)$ \\
& 0.059 & 0.064 & 0.011 & 0.016 & 0.003 & 0.003 \\
Observations & 6448 & 6448 & 15860 & 15860 & 15857 & 15857 \\
\hline Pre-HAART treatment group mean & 0.109 & 0.109 & 0.175 & 0.175 & 0.086 & 0.086 \\
Mean & 0.062 & 0.062 & 0.118 & 0.118 & 0.050 & 0.050 \\
Pseudo $R^{2}$ & 0.028 & 0.058 & 0.006 & 0.039 & 0.010 & 0.049 \\
\hline Black Sample & & & & & & \\
Treatment $\times$ HAART & $-0.021^{* *}$ & $-0.023^{* *}$ & $-0.044^{* *}$ & $-0.043^{* *}$ & $-0.021^{* *}$ & $-0.018^{*}$ \\
& $(0.011)$ & $(0.011)$ & $(0.020)$ & $(0.021)$ & $(0.010)$ & $(0.010)$ \\
Observations & 0.049 & 0.041 & 0.031 & 0.035 & 0.028 & 0.057 \\
Pre-HAART treatment group mean & 4097 & 4097 & 9047 & 9047 & 9044 & 9044 \\
Mean & 0.141 & 0.141 & 0.193 & 0.193 & 0.082 & 0.082 \\
Pseudo $R^{2}$ & 0.069 & 0.069 & 0.140 & 0.140 & 0.050 & 0.050 \\
\hline Basic controls & 0.039 & 0.058 & 0.006 & 0.047 & 0.012 & 0.069 \\
\hline \hline
\end{tabular}

This table shows the marginal effects of the interaction term from the difference-in-differences probit models. Standard errors are presented in parenthesis, and p-values are found below. Basic controls include age at visit, age squared, age cubed, race (Caucasian omitted), and site of visit (Chicago omitted). In all specifications, errors are clustered at the individual level. The sample is restricted to women who participated in the study for at least 15 visits ( 7.5 years). 
Table A5: Normalized Differences

\begin{tabular}{lc}
\hline \hline & HIV,+ Healthy Sample \\
\hline African American & 0.08 \\
Hispanic & -0.03 \\
White & -0.02 \\
Other race & -0.16 \\
Max income pre-HAART & -0.00 \\
Max inc pre-HAART $<6000$ & 0.00 \\
Max inc pre-HAART 6001-12000 & 0.02 \\
Max inc pre-HAART 12001-18000 & -0.03 \\
Max inc pre-HAART 18001-24000 & 0.04 \\
Max inc pre-HAART 24001-30000 & -0.09 \\
Max inc pre-HAART $>30000$ & 0.04 \\
Age at visit & 0.19 \\
Bronx & 0.05 \\
Brooklyn & -0.07 \\
DC & 0.24 \\
LA & -0.09 \\
Less than HS & -0.08 \\
HS graduate & 0.00 \\
Some college & 0.08 \\
College graduate & 0.09 \\
Married pre-HAART & 0.15 \\
Lived with kids at baseline & 0.09 \\
Experienced DV pre-HAART & -0.13 \\
Cocaine use pre-HAART & -0.05 \\
Heroin use pre-HAART & 0.07 \\
Employed pre-HAART & -0.13 \\
Smokes & -0.09 \\
Drinks & -0.01 \\
Time since ${ }^{\text {st }}+$ HIV test & 0.16 \\
\hline Observations & 263 \\
\hline \hline
\end{tabular}

This table shows normalized differences between the treatment group and the control group. 
Table A6: Propensity Score Results

\begin{tabular}{lcc|cc}
\hline \hline & \multicolumn{2}{c}{ Pre-HAART } & \multicolumn{2}{c}{ Post-HAART } \\
& Linear & Quadratic & Linear & Quadratic \\
\hline Panel A: Treatment vs Control Group Women & & & \\
Domestic violence & & & & \\
& $(0.0093$ & -0.0001 & $-0.0337^{* * *}$ & $-0.0388^{* * *}$ \\
& 1329 & $(0.0190)$ & $(0.0121)$ & $(0.0123)$ \\
& & 1294 & 1697 & 1675 \\
Heroin use & 0.0084 & & & \\
& $(0.0112)$ & $(0.0119)$ & $(0.0053)$ & $(0.0053)$ \\
& 1435 & 1325 & 5192 & 4722 \\
Cocaine use & & & \\
& 0.0149 & 0.0032 & 0.0022 & -0.0050 \\
& $(0.0151)$ & $(0.0158)$ & $(0.0084)$ & $(0.0082)$ \\
& 1351 & 1348 & 4670 & 4721 \\
\hline \hline
\end{tabular}

This table shows the average treatment effects from propensity score matching. We show findings from both a linear and quadratic specification. Controls following the algorithm proposed by Imbens (2015) are included. For each outcome, we show the estimated coefficient, standard error in parenthesis, and number of observations. 
Table A7: Joint Estimation: Domestic Violence and Cocaine Use, Treatment and Control Groups

\begin{tabular}{|c|c|c|}
\hline & {$[1]$} & {$[2]$} \\
\hline \multicolumn{3}{|l|}{$\begin{array}{l}\text { Panel A: Full Sample } \\
\text { Domestic Violence }\end{array}$} \\
\hline HAART available & $\begin{array}{c}-.374^{* * *} \\
(.074)\end{array}$ & $\begin{array}{c}-.248^{* * *} \\
(.084)\end{array}$ \\
\hline Treatment group & $\begin{array}{l}-.070 \\
(.115)\end{array}$ & $\begin{array}{l}-.028 \\
(.116)\end{array}$ \\
\hline Treatment $\times$ HAART & $\begin{array}{l}-.188 \\
(.117)\end{array}$ & $\begin{array}{c}-.201^{*} \\
(.121)\end{array}$ \\
\hline Obs. & 6669 & 6669 \\
\hline \multicolumn{3}{|l|}{ Cocaine Use } \\
\hline HAART available & $\begin{array}{l}-.154^{* *} \\
(.061)\end{array}$ & $\begin{array}{l}-.190^{* * *} \\
(.068)\end{array}$ \\
\hline Treatment group & $\begin{array}{l}.020 \\
(.126)\end{array}$ & $\begin{array}{l}.047 \\
(.125)\end{array}$ \\
\hline Treatment $\times$ HAART & $\begin{array}{r}-.123 \\
(.099)\end{array}$ & $\begin{array}{l}-.121 \\
(.101)\end{array}$ \\
\hline Obs. & 6669 & 6669 \\
\hline Mean domestic violence & 0.063 & 0.063 \\
\hline Mean cocaine use & 0.120 & 0.120 \\
\hline Rho & $0.331^{* * *}$ & $0.325^{* * *}$ \\
\hline \multicolumn{3}{|c|}{$\begin{array}{l}\text { Panel B: Black Sample } \\
\text { Domestic Violence }\end{array}$} \\
\hline HAART available & $\begin{array}{l}-.418^{* * *} \\
\quad(.092)\end{array}$ & $\begin{array}{c}-.331^{* * *} \\
(.098)\end{array}$ \\
\hline Treatment group & $\begin{array}{l}-.011 \\
(.140)\end{array}$ & $\begin{array}{l}.036 \\
(.141)\end{array}$ \\
\hline Treatment $\times$ HAART & $\begin{array}{c}-.262^{*} \\
(.145)\end{array}$ & $\begin{array}{c}-.279^{*} \\
(.148)\end{array}$ \\
\hline Obs. & 4280 & 4280 \\
\hline \multicolumn{3}{|l|}{ Cocaine Use } \\
\hline HAART available & $\begin{array}{c}-.151^{* *} \\
(.077)\end{array}$ & $\begin{array}{c}-.209^{* *} \\
(.085)\end{array}$ \\
\hline Treatment group & $\begin{array}{l}.178 \\
(.155)\end{array}$ & $\begin{array}{l}.211 \\
(.159)\end{array}$ \\
\hline Treatment $\times$ HAART & $\begin{array}{r}-.151 \\
(.119)\end{array}$ & $\begin{array}{r}-.141 \\
(.122)\end{array}$ \\
\hline Obs. & 4280 & 4280 \\
\hline Mean domestic violence & 0.069 & 0.069 \\
\hline Mean cocaine use & 0.130 & 0.130 \\
\hline Rho & $0.319^{* * *}$ & $0.319^{* * *}$ \\
\hline Basic controls & $\mathrm{N}$ & $\mathrm{Y}$ \\
\hline
\end{tabular}

This table shows difference-in-differences estimates from a bivariate probit model where the outcome variables are domestic violence and cocaine use and the control group consists of relatively healthy HIV + women. Basic controls include age at visit, age squared, age cubed, race (Caucasian omitted), and site of visit (Chicago omitted). In all specifications, errors are clustered at the individual level. 
Table A8: Joint Estimation: Domestic Violence and Heroin Use, Treatment and Control Groups

\begin{tabular}{|c|c|c|}
\hline & {$[1]$} & {$[2]$} \\
\hline \multicolumn{3}{|l|}{ Panel A: Full Sample } \\
\hline HAART available & $\begin{array}{c}-.365^{* * *} \\
(.075)\end{array}$ & $\begin{array}{c}-.234^{* * *} \\
(.085)\end{array}$ \\
\hline Treatment group & $\begin{array}{l}-.065 \\
(.115)\end{array}$ & $\begin{array}{l}-.027 \\
(.116)\end{array}$ \\
\hline Treatment $\times$ HAART & $\begin{array}{c}-.199^{*} \\
(.117)\end{array}$ & $\begin{array}{c}-.211^{*} \\
(.121)\end{array}$ \\
\hline Obs. & 6669 & 6669 \\
\hline \multicolumn{3}{|l|}{ Heroin Use } \\
\hline HAART available & $\begin{array}{l}-.055 \\
(.069)\end{array}$ & $\begin{array}{l}-.125 \\
(.081)\end{array}$ \\
\hline Treatment group & $\begin{array}{l}.133 \\
(.144)\end{array}$ & $\begin{array}{l}.153 \\
(.145)\end{array}$ \\
\hline Treatment $\times$ HAART & $\begin{array}{c}-.318^{* *} \\
(.127)\end{array}$ & $\begin{array}{c}-.306^{* *} \\
(.131)\end{array}$ \\
\hline Obs. & 6669 & 6669 \\
\hline Mean domestic violence & 0.063 & 0.063 \\
\hline Mean heroin use & 0.051 & 0.051 \\
\hline Rho & $0.233^{* * *}$ & $0.262^{* * *}$ \\
\hline \multicolumn{3}{|c|}{$\begin{array}{l}\text { Panel A: Black Sample } \\
\text { Domestic Violence }\end{array}$} \\
\hline HAART available & $\begin{array}{l}-.409^{* * *} \\
\quad(.092)\end{array}$ & $\begin{array}{c}-.319^{* * *} \\
(.098)\end{array}$ \\
\hline Treatment group & $\begin{array}{l}-.009 \\
(.140)\end{array}$ & $\begin{array}{l}.033 \\
(.141)\end{array}$ \\
\hline Treatment $\times$ HAART & $\begin{array}{c}-.272^{*} \\
(.146)\end{array}$ & $\begin{array}{r}-.290^{*} \\
(.148)\end{array}$ \\
\hline Obs. & 4280 & 4280 \\
\hline \multicolumn{3}{|l|}{ Heroin Use } \\
\hline HAART available & $\begin{array}{l}-.087 \\
(.081)\end{array}$ & $\begin{array}{l}-.229^{* * *} \\
(.081)\end{array}$ \\
\hline Treatment group & $\begin{array}{l}.161 \\
(.178)\end{array}$ & $\begin{array}{l}.170 \\
(.177)\end{array}$ \\
\hline Treatment $\times$ HAART & $\begin{array}{c}-.298^{*} \\
(.155)\end{array}$ & $\begin{array}{l}-.253 \\
(.159)\end{array}$ \\
\hline Obs. & 4280 & 4280 \\
\hline Mean domestic violence & 0.069 & 0.069 \\
\hline Mean heroin use & 0.046 & 0.046 \\
\hline Rho & $0.272^{* * *}$ & $0.289^{* * *}$ \\
\hline Basic controls & $\overline{\mathrm{N}}$ & $\mathrm{Y}$ \\
\hline
\end{tabular}

This table shows difference-in-differences estimates from a bivariate probit model where the outcome variables are domestic violence and heroin use and the control group consists of relatively healthy HIV + women. Basic controls include age at visit, age squared, age cubed, race (Caucasian omitted), and site of visit (Chicago omitted). In all specifications, errors are clustered at the individual level. 
Table A9: Employment, Cocaine Use and Health

\begin{tabular}{lcc}
\hline \hline Current Cocaine Use & & \\
Cocaine & $-.065^{* * *}$ & $-.062^{* * *}$ \\
CD4 count &. & $.0001^{* * *}$ \\
CD4 squared &. & $-7.20 \mathrm{e}-08^{* * *}$ \\
Age & .017 & .019 \\
Age squared & .0001 & .00005 \\
Age cubed & $-3.92 \mathrm{e}-06$ & $-3.63 \mathrm{e}-06$ \\
Obs. & 9952 & 9952 \\
$R^{2}$ & .008 & .01 \\
\hline Cocaine Use Last Year & & \\
Stimulant use last year & $-.031^{*}$ & $-.030^{*}$ \\
CD4 count &. & $.0001^{* * *}$ \\
CD4 squared &. & $-7.49 \mathrm{e}-08^{* * *}$ \\
Age & .017 & .020 \\
Age squared & .00008 & .00003 \\
Age cubed & $-3.84 \mathrm{e}-06$ & $-3.53 \mathrm{e}-06$ \\
Obs. & 9952 & 9952 \\
$R^{2}$ & .007 & .008 \\
\hline Cocaine Use Two Years Ago & \\
Stimulant use two years ago & -.003 & -.004 \\
CD4 count &. & $.0001^{* * *}$ \\
CD4 squared &. & $-7.54 \mathrm{e}-08^{* * *}$ \\
Age & .017 & .020 \\
Age squared & .00009 & .00004 \\
Age cubed & $-3.88 \mathrm{e}-06$ & $-3.57 \mathrm{e}-06$ \\
Obs. & 9952 & 9952 \\
$R^{2}$ & .006 & .008 \\
\hline Mean & .333 & .333 \\
\hline \hline
\end{tabular}

This table shows results from an OLS model with individual level fixed effects where the outcome is employment at the time of visit. Each panel shows results from including current health and cocaine use from a different point in time: current, use last year, and use two years ago. 
Table A10: Employment, Heroin Use and Health

\begin{tabular}{lcc}
\hline Current Heroin Use & & \\
Used heroin SLV & $-.044^{* *}$ & $-.043^{* *}$ \\
CD4 count &. & $.0001^{* * *}$ \\
CD4 squared &. & $-7.44 \mathrm{e}-08^{* * *}$ \\
Age & .018 & .021 \\
Age squared & .00006 & .00002 \\
Age cubed & $-3.68 \mathrm{e}-06$ & $-3.38 \mathrm{e}-06$ \\
Obs. & 9947 & 9947 \\
$R^{2}$ & .007 & .008 \\
\hline Heroin Use Last Year & & \\
Heroin use last year & -.028 & -.028 \\
CD4 count &. & $.0001^{* * *}$ \\
CD4 squared &. & $-7.48 \mathrm{e}-08^{* * *}$ \\
Age & .018 & .020 \\
Age squared & .00007 & .00002 \\
Age cubed & $-3.72 \mathrm{e}-06$ & $-3.41 \mathrm{e}-06$ \\
Obs. & 9947 & 9947 \\
$R^{2}$ & .007 & .008 \\
\hline Heroin Use Two Years & Ago & \\
Heroin use two years ago & $-.029^{*}$ & $-.031^{*}$ \\
CD4 count &. & $.0001^{* * *}$ \\
CD4 squared &. & $-7.57 \mathrm{e}-08^{* * *}$ \\
Age & .018 & .021 \\
Age squared & .00006 & $8.85 \mathrm{e}-06$ \\
Age cubed & $-3.66 \mathrm{e}-06$ & $-3.34 \mathrm{e}-06$ \\
Obs. & 9947 & 9947 \\
$R^{2}$ & .007 & .008 \\
\hline Mean & .333 & .333 \\
\hline \hline
\end{tabular}

This table shows results from an OLS model with individual level fixed effects where the outcome is employment at the time of visit. Each panel shows results from including current health and heroin use from a different point in time: current, use last year, and use two years ago. 